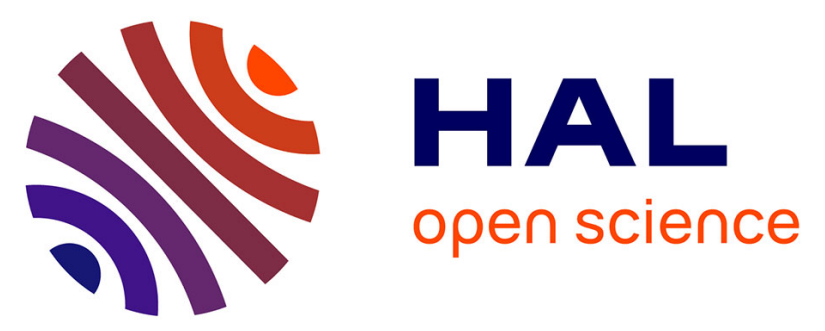

\title{
Influence of bulk concentration on the organisation of molecules at a membrane surface and flux decline during reverse osmosis of an anionic surfactant
}

Zhaohuan Mai, Vincent Butin, Mohammed Rakib, Haochen Zhu, Murielle Rabiller-Baudry, Estelle Couallier

\section{To cite this version:}

Zhaohuan Mai, Vincent Butin, Mohammed Rakib, Haochen Zhu, Murielle Rabiller-Baudry, et al.. Influence of bulk concentration on the organisation of molecules at a membrane surface and flux decline during reverse osmosis of an anionic surfactant. Journal of Membrane Science, 2016, 499, pp. 257-268. 10.1016/j.memsci.2015.10.012 . hal-01216295

\section{HAL Id: hal-01216295 \\ https://hal-univ-rennes1.archives-ouvertes.fr/hal-01216295}

Submitted on 14 Jan 2016

HAL is a multi-disciplinary open access archive for the deposit and dissemination of scientific research documents, whether they are published or not. The documents may come from teaching and research institutions in France or abroad, or from public or private research centers.
L'archive ouverte pluridisciplinaire HAL, est destinée au dépôt et à la diffusion de documents scientifiques de niveau recherche, publiés ou non, émanant des établissements d'enseignement et de recherche français ou étrangers, des laboratoires publics ou privés. 


\section{Influence of bulk concentration on the organisation of molecules at a membrane surface and flux decline during reverse osmosis of an anionic surfactant}

Zhaohuan $\mathrm{Mai}^{\mathrm{a}}$, Vincent Butin ${ }^{\mathrm{a}}$, Mohammed Rakib ${ }^{\mathrm{a}}$, Haochen Zhu ${ }^{\mathrm{a}}$, Murielle Rabiller-Baudry ${ }^{\mathrm{b}}$, Estelle Couallier ${ }^{\mathrm{a}, \mathrm{c}^{*}}$

Graphical abstract
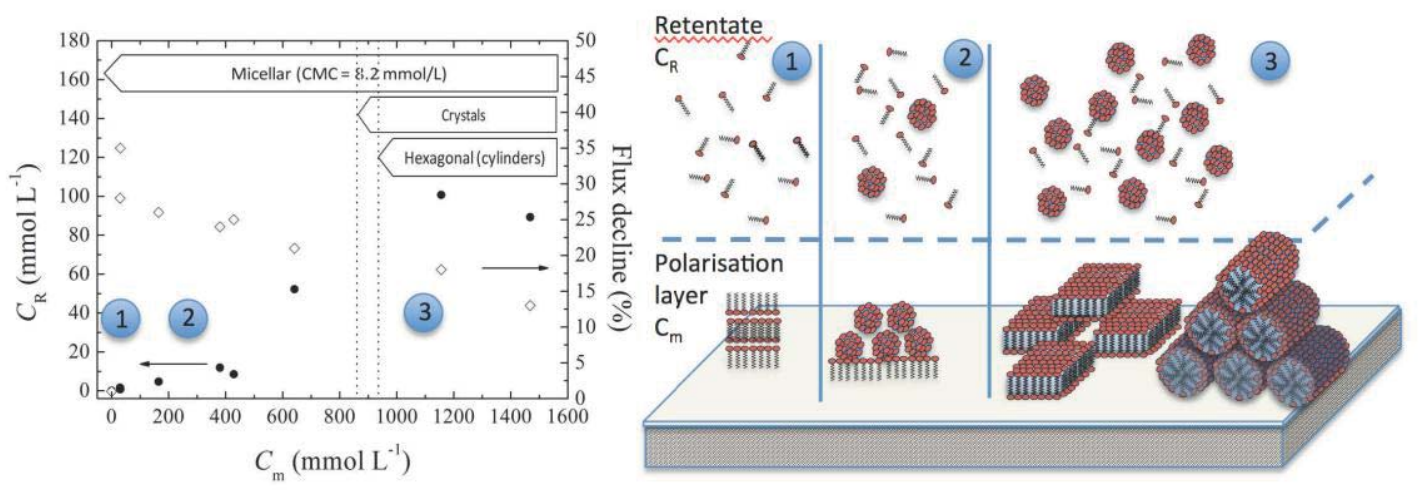

\section{Highlights}

The fouling of a reverse osmosis membrane by amphiphilic molecules is studied.

Permeate flux, contact angles, mass balance are combined to characterize the fouling.

A local organisation at the interface is deduced from the surfactant phase diagram.

\section{Keywords}

Reverse osmosis

Membrane fouling

Surfactants aggregation

Sodium dodecyl sulfate 


\title{
Influence of bulk concentration on the organisation of molecules at a membrane surface and flux decline during reverse osmosis of an anionic surfactant
}

\author{
Zhaohuan Mai ${ }^{\mathrm{a}, \mathrm{b}}$, Vincent Butin ${ }^{\mathrm{a}}$, Mohammed Rakib ${ }^{\mathrm{a}}$, Haochen Zhu ${ }^{\mathrm{a}}$, Murielle \\ Rabiller-Baudry ${ }^{\mathrm{c}}$, Estelle Couallier ${ }^{\mathrm{a}, \mathrm{d}^{*}}$ \\ ${ }^{a}$ Laboratoire de Génie des Procédés et Matériaux, Ecole Centrale Paris,Grande Voie des Vignes, \\ 92295 Châtenay-Malabry, France \\ ${ }^{b}$ Energy research institute, Jiangxi Academy of Sciences, 7777 Changdong Road, 330096 Nanchang, \\ China
}

${ }^{c}$ Université de Rennes 1, Institut des Sciences Chimiques de Rennes-UMR CNRS 6226, 263 avenue du Général Leclerc, 35000 Rennes, France

${ }^{d}$ GEPEA-UMR CNRS 6144, 37 boulevard de l'Université, BP 406, 44602 Saint Nazaire, France

*Corresponding author: estelle.couallier@univ-nantes.fr; (+33)240172667 ;

\section{Abstract}

Surfactants are extensively used in household and industrial products. Several processes exist to treat industrial wastewaters, including membrane filtration such as ultrafiltration, nanofiltration and reverse osmosis (RO). We studied fouling of RO membranes during filtration of aqueous anionic surfactant solutions under different conditions. The aim was to describe the local organisation of the surfactant at the membrane interface. To this end, the typical surfactant sodium dodecyl sulfate (SDS) and a polyamide membrane (SG, GE Water \& Process Technologies) were selected. A marked surfactant mass loss was experimentally quantified and attributed to the accumulation of surfactants on the membrane surface and adsorption on the non-membrane materials in the filtration system. The concentration of surfactant in the polarisation layer compared with the SDS phase diagram, combined with contact angle measurements and flux decline analysis, enabled us to deduce a structure for the fouling. The fouling layer presented different structures according to the surfactant concentration: from a dense hydrophobic layer at very low concentration to a lamellar hexagonal phase in the gel layer at concentrations above $35 \mathrm{wt} \%$ in water. 


\section{Introduction}

Surfactants are amphiphilic molecules are extensively used in household products, detergents, industrial processes and pesticide formulations for their fundamental properties, such as micellisation in solutions and adsorption on interfaces/surfaces [1,2]. Owing to their frequent use, they may also persist in wastewater treatment systems at relatively high concentrations. To avert serious health and environmental problems resulting from direct and indirect release of surfactants, effective clean and sustainable methods are needed to remove surfactants from industrial wastewater to prevent their release into the environment.

Various approaches have shown that membrane filtration, such as ultrafiltration (UF), nanofiltration (NF) and reverse osmosis (RO), is an effective technique to remove surfactants from effluents $[3,4]$. Membrane technology stands out as being environment-friendly and easy to operate, and requiring no added chemicals. The best retention of surfactants has been achieved by the RO process [4,5], although surfactant adsorption on the active layer of the membranes led to folding and thus penetration (i.e. partitions) inside the membrane of this, as other trace organics, and some weak leakage [6]. However, accumulation of matter may occur during membrane filtration of surfactants, resulting in severe flux decline [4,7-12]. Classic modelling of RO membrane fouling can take into account the following phenomena: adsorption (accumulation of solutes on the external and internal surfaces, changing membrane hydrophobicity), cake formation (accumulation of particles on the membrane forming a second porous media) and concentration polarisation (rise of solute concentration in the layer near the membrane surface). Understanding the behaviour of surfactants at the RO membrane interface in filtration requires deeper investigation. In an earlier study, a theoretical approach was taken to investigate the interaction between the surfactant molecules [13].

The aim of this work was to describe the local organisation of an anionic surfactant at the membrane interface during RO filtration of synthetic solutions. This work is based on the quantification of accumulated matter compared with the surfactant phase diagram, linked to flux decline and hydrophobicity modification.

\subsection{Surfactants in solution}

A surfactant molecule bears at least one hydrophilic group comprising an ionised or polar assembly, and a hydrophobic moiety made up of carbonated chains. Owing to their amphiphilic nature, surfactants adsorb preferentially at interfaces, and form aggregates called micelles when they reach their critical micelle concentration (CMC). For sufficiently low monomer concentrations, most of the molecules in the solution are isolated. Once the concentration reaches the $\mathrm{CMC}$, addition of surfactant molecules results in the formation of 


\section{ACCEPTED MANUSCRIPT}

micelles, leaving monomer concentrations largely unchanged at the CMC value [4]. The $\mathrm{CMC}$ values are influenced by the nature of the hydrophobic tail and hydrophilic head, $\mathrm{pH}$, ionic strength, temperature, etc.

When the mass fraction of surfactants in water rises, the molecules can form more complex aggregates as described in phase diagrams by Kekicheff and co-workers [14-16]. The binary phase diagram of SDS in $\mathrm{D}_{2} \mathrm{O}$ is presented in Fig. 1. The organisation of SDS in water $\left(\mathrm{H}_{2} \mathrm{O}\right)$ is considered to be similar. The structures of many liquid and semi-liquid phases have been identified, and classified structurally. The most common structures are the micellar phase (mic), the liquid crystal phase (C), where local organisation in lamellar fragments occurs, the lamellar phase (L) where bilayers of amphiphilic molecules are separated by water layers, and the hexagonal or reversed hexagonal phases $(\mathrm{H})$, where cylinders of amphiphile (or water) are arranged in a two-dimensional hexagonal lattice. Four intermediate phases have also been identified between the hexagonal and the lamellar phases: a two-dimensional monoclinic phase $(\mathrm{M})$, a rhombohedral phase $(\mathrm{R})$, a cubic phase $(\mathrm{Q})$ and a tetragonal phase $(\mathrm{T})$. In the cubic phase, the primary units are short rodlike aggregates, connected at each end to form two interwoven, but otherwise independent three-dimensional networks. In what follows, the generic word "gel" will be used to describe the accumulation of surfactants organised in three-dimensional structures in the aqueous phase; no polymerisation occurs here. Since the experiments with the RO process in this work were carried out at $25^{\circ} \mathrm{C}$, the phase diagram of SDS at this temperature is discussed. At $25^{\circ} \mathrm{C}$, the SDS is in a micellar phase below $37 \mathrm{wt} \%$, and then forms a hexagonal phase, in equilibrium with micelles between $37 \%$ and $40 \mathrm{wt} \%$. In the range of $40 \mathrm{wt} \%$ to $86 \mathrm{wt} \%$, the hexagonal and liquid crystal phases co-occur. There is only a liquid crystal phase above $86 \mathrm{wt} \%$. 


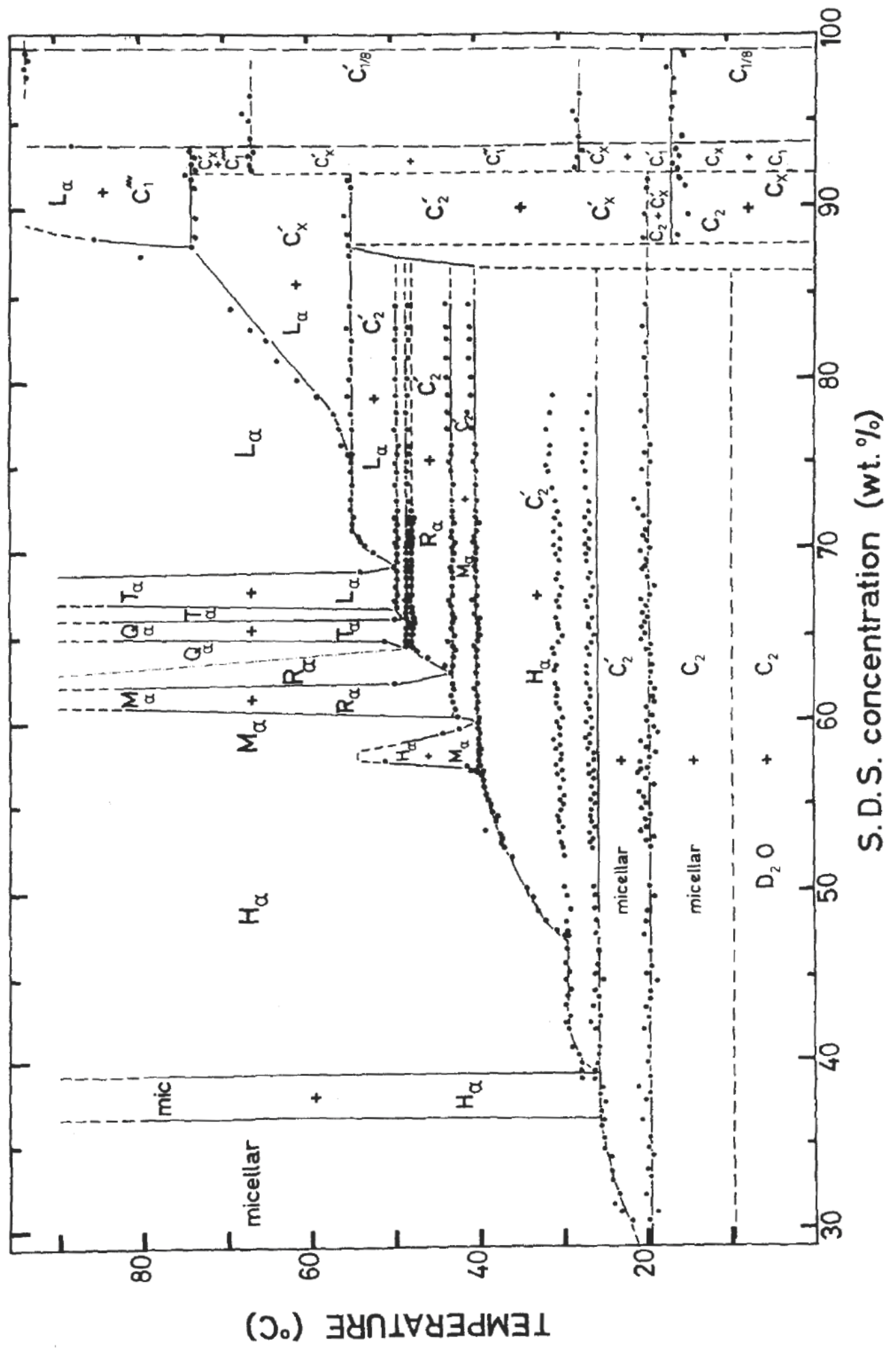

Fig. 1. Schematic SDS- $\mathrm{D}_{2} \mathrm{O}$ phase diagram suggested by Kekicheff et al. [14]. Compositions are expressed as SDS weight percentage. Different structures are labelled according to the symmetry of their lattice: mic: micellar phase; $\mathrm{H} \alpha$ : hexagonal phase; $\mathrm{M} \alpha$ : two-dimensional monoclinic phase; $\mathrm{R} \alpha$ : rhombohedral phase; Q $\alpha$ : cubic phase; T $\alpha$ : tetragonal phase; L $\alpha$ : lamellar phase; C: crystal phase. 


\subsection{Surfactant at liquid-solid interface}

The adsorption of surfactants at a liquid-solid interface is governed by a number of forces such as electrostatic interactions, hydrogen bonding, lateral interactions between the adsorbed species, hydrophobic/hydrophilic interactions between the substrate and the surfactants, and solvation and desolvation of the surfactants, as described elsewhere [17-21]. Classical model surfaces are either positively or negatively charged in the aqueous medium by ionisation/dissociation of surface groups or by the adsorption of ions from solution on a previously uncharged surface [20]. Based on previous approaches, several models of surfactant adsorption on solids and corresponding structures have been proposed.

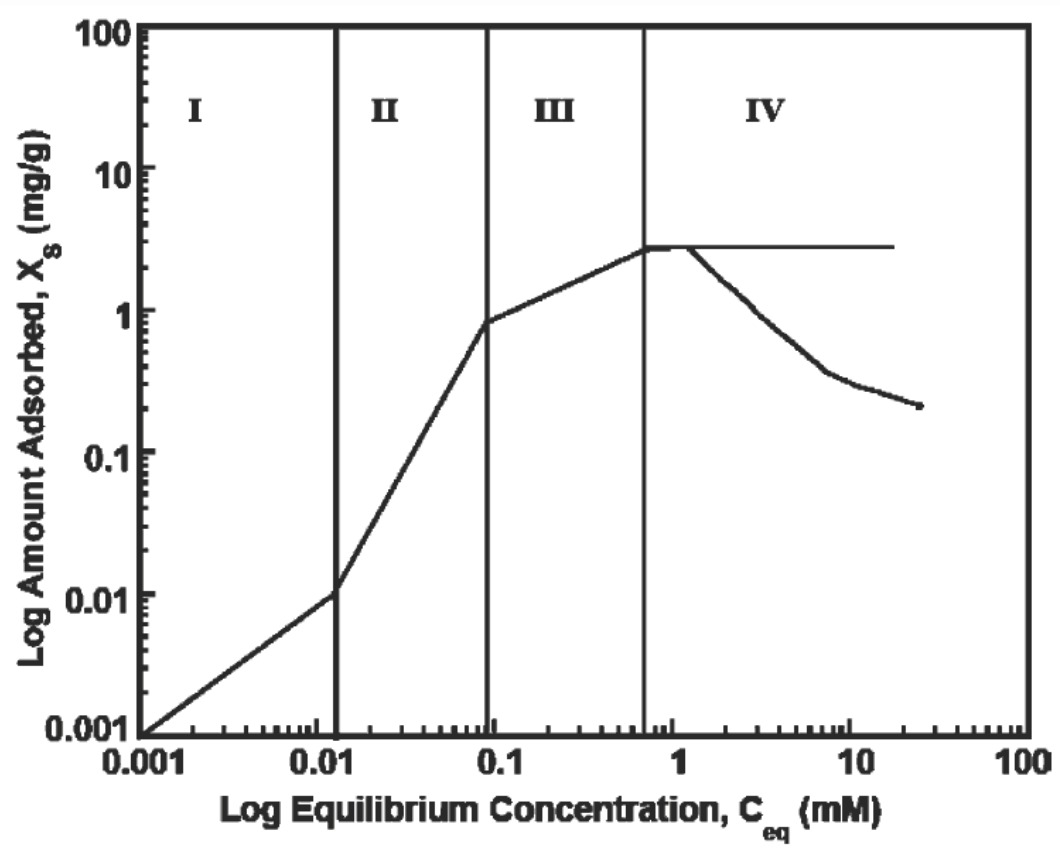

Fig. 2. Schematic presentation of typical four-region adsorption isotherm [20]

A typical isotherm of ionic surfactant adsorption on an oppositely charged solid surface can be split into four regions when plotted on a log-log scale, as shown in Fig. 2. According to Paria et al. [20], in region I, the concentration of surfactant is low and surfactant molecules are electrostatically adsorbed on the solid surface. At this stage, the adsorption obeys Henry's law: the adsorption amount increases linearly with surfactant concentration. In region II, due to lateral interaction between hydrophobic chains of the adsorbed monomers, surface aggregation of surfactants develops continuously, with a sudden increase in the curve. These surfactant aggregates, termed admicelles or hemimicelles by various investigators, are assumed to be largely flat. Region III shows a slower rate of adsorption than region II. At this stage, the solid surface is electrically neutralised by the adsorbed surfactant ions; with no 


\section{ACCEPTED MANUSCRIPT}

electrostatic interaction between the surfactants and the surface, the adsorption takes place due only to lateral attraction, with a reduced slope. Region IV is the plateau region above the CMC. Sometimes region IV shows a maximum, due to the presence of trace surface-active impurities [20,21].

The adsorption of surfactants on a solid phase with the same charge occurs through hydrophobic adsorption to limit the contact between surfactant head and solid. The adsorption of non-ionic surfactants on a solid-liquid interface is considered to occur predominantly through hydrogen bonding interactions at low concentrations, and through lateral interactions at high concentrations (for more details see earlier reviews [20,21]).

From experimental results, a number of surface aggregate types, such as monolayer, hemi-cylinders, hemi-micelles, full cylinders, spheres or bilayers, etc., have been observed on different hydrophobic and hydrophilic surfaces [18-21]. In general, short chain surfactants form monolayers. Surfactants with longer chains self-organise in hemi-cylinders on hydrophobic surfaces due to hydrophobic interactions between the substrates and the tail groups of the surfactants, but form full cylinders or spheres on hydrophilic substrates. However, some investigators have found more than one aggregate structure on the same surface under different conditions. Hannes and co-workers even found wormlike micelles with different morphologies on rough gold surfaces [17].

Different structures of surface aggregates on solid surfaces were also suggested by simulation studies [22-24]. The shapes of hemi-cylindrical and spherical aggregates at water/graphite and water $\mathrm{TiO}_{2}$ interfaces are the most often reported [22,24]. In a molecular dynamics simulation study, SDS molecules aggregated into an irregular shape on the top of a hemi-cylinder adsorbed on a graphite surface at high concentrations [23]. The system undergoes a structure transition characterised by an increase in the number of well-defined layers of aggregates close to the graphite surface as the surfactant concentration increases.

\subsection{Surfactants and membranes}

In a surfactant-membrane system, the behaviour of surfactants at the membrane surface depends on several chemical and physical factors, including feed fluid composition (e.g. surfactant structure, concentration, $\mathrm{pH}$, ionic strength, temperature), membrane properties (e.g. chemical composition inducing charge and hydrophobicity, roughness), and hydrodynamic conditions [6].

The literature describes surfactant-membrane interactions for anionic [25] and non-ionic [26] surfactants as related to the membrane's charge (polar groups) and hydrophobicity (carbonated backbone). With active layers made of aromatic thin film polyamide or cellulose esters, most RO and NF membranes have a global negative charge at $\mathrm{pH}$ above 5. However, 


\section{ACCEPTED MANUSCRIPT}

we can consider that the polyamide RO membrane used in this work can present positive and negative charges due to non-polymerised external functions.

Negative membrane charges increase anionic surfactant rejection [25]. At $\mathrm{pH}$ below $\mathrm{p} K_{\mathrm{a}}$ and high ionic strength, electrostatic repulsion is reduced, while membrane fouling and flux decline are increased [27], [28]: Boussu compared the filtration of anionic, cationic and non-ionic surfactants with various NF membranes [28], and found that surfactant adsorption and pore blocking led to flux decline. For an anionic surfactant, electrostatic repulsion increased the rejection and lowered the flux decline for each membrane compared with a non-ionic surfactant.

Based on contact angle measurements, the apolar surface tensions $\gamma_{\mathrm{sv}}{ }^{\mathrm{LW}}$ of polyamide and cellulose acetate membranes lie in the range $32-39 \mathrm{~mJ} \mathrm{~m}^{-2}$ [5], but the polar components (including electron pair acceptors, namely atoms with an electron vacancy in their valency shell, and electron pair donor components) were different. The electron donor component of the surface tension, $\gamma_{\text {sv }}^{-}$, was predominant for most membranes, which is readily understandable given the presence of several oxygen atoms in the membrane composition. Substantial apolar interactions can nevertheless be expected with these kinds of membranes due to the carbon skeleton of the polymers, as well as polar interactions preferably with electron acceptor molecules.

Literature reports on RO membrane fouling by surfactants are scant [5,29-33]. These studies, attribute flux decline to concentration polarisation [29], gel layer formation [30,31], entrapment of surfactant molecules in the top layer and their accumulation on the membrane surface $[5,32]$, and modification of membrane surface charge and hydrophobicity caused by the adsorption of the surfactant [33]. The modification of the membrane surface due to accumulation of surfactants was studied mainly by contact angle and zeta potential measurements [34-46] [47]. However, to our knowledge, few studies have precisely quantified the surfactant accumulated on the membrane, and no local organisation of surfactant at the membrane interface has ever been described.

Our objective was to combine experiments and phase diagram [14] to propose a better description of the fouling structure of anionic surfactant at the RO membrane interface.

Sodium dodecyl sulfate (SDS), widely used in many cleaning and hygiene products, and probably the most widely used anionic surfactant, was selected for the fouling experiments. First, a series of filtration experiments with different surfactant concentrations was performed to evaluate RO membrane performance (retention rate, permeability, cleanability) and the accumulation of surfactants was quantified. Static adsorption tests were compared with fouling in dynamic conditions. Contact angle measurements were then made by the sessile drop method to compare membrane surface properties before and after the filtration of surfactant solution. After a detailed presentation of the results, the whole data set is discussed 


\section{ACCEPTED MANUSCRIPT}

and compared with the SDS phase diagram. Finally a structure of RO membrane fouling is proposed versus the surfactant concentration.

\section{Materials and methods}

\subsection{Surfactant solutions}

An anionic surfactant, sodium dodecyl sulfate (SDS), was used as a model surfactant due to its commercial availability and its widespread use in commercial detergents. Compared with other surfactants, SDS is soluble in water and easy to rinse out. According to the manufacturer (Sigma-Aldrich), SDS (purity $\geqslant 99.0 \%$ ) has a molar mass of $288.38 \mathrm{~g} \mathrm{~mol}^{-1}$ and a solubility of $250 \mathrm{~g} \mathrm{~L}^{-1}$ in water at $20^{\circ} \mathrm{C}$. The reported value of CMC in pure water lies in the range 8.0$8.4 \mathrm{mmol} \mathrm{L}^{-1}$ at $25^{\circ} \mathrm{C}$, and the aggregation number at this concentration ranges from 54 to 64 [48]. The CMC of SDS was determined in the laboratory at $25^{\circ} \mathrm{C}$ by measuring the conductivity values of SDS solutions at various concentrations. This methods revealed a CMC value of $8.2 \mathrm{mmol} \mathrm{L}^{-1}$ (data not presented), close to literature values.

The surfactant samples were used as received without further purification. Solutions were prepared using distilled water, and homogenised by gentle magnetic stirring for $30 \mathrm{~min}$ to ensure complete dissolution.

\subsection{RO membranes}

Thin film composite polyamide SG membranes (GE Water \& Process Technologies, USA) were selected for the tests. The RO membrane was characterised by high sodium chloride rejection (average and minimum $\mathrm{NaCl}$ rejection of $98.5 \%$ and $97 \%$, respectively) and a smooth, fouling-resistant membrane surface. Typical thin film composite RO membranes are composed of three layers: a top dense polyamide layer responsible for selectivity, a microporous polysulfone layer, and a non-woven fabric layer as support [32]. Akin et al.[49] found that the top active layer of SG membrane was about 100 to $150 \mathrm{~nm}$, made of polyesteramide laid on a polysulfone support with a thickness of $60 \mu \mathrm{m}$. The membrane has been reported to be negatively charged in contact with solutions typical of wastewater effluents, with an isoelectric point lower than $\mathrm{pH} 4$ [32], confirmed by measurements made at UMR CNRS 6226. In the present study, average $\mathrm{pH}$ was equal to 6.

\subsection{Analytical methods}

A reversed phase high performance liquid chromatography (HPLC) method was used to quantify SDS. HPLC measurements were made with an analytical system composed of a 


\section{ACCEPTED MANUSCRIPT}

Hitachi L-2130 gradient pump (Eurosep Instruments), a Rheodyne valve with a $40 \mu \mathrm{L}$ injection loop, an Eclipse Zorbax XDB-C8 analytical column (Agilent Technologies, diameter $4.6 \mathrm{~mm}$, length $150 \mathrm{~mm}$, particle size $5 \mu \mathrm{m}$, pore size $80 \AA$ ), and a column oven at $35^{\circ} \mathrm{C}$. The mobile phase with methanol: water 70:30 (v:v) was set at an isocratic flow rate of $1.0 \mathrm{~mL}$ $\min ^{-1}$. An evaporative light scattering detector (ELSD, Chromachem, Eurosep Instrument) was used for the detection and quantification of SDS. The parameters of the ELSD detector were as follows: attenuation 2, nitrogen pressure 1.5 bar, nebulisation and evaporation temperatures 50 and $70{ }^{\circ} \mathrm{C}$, respectively.

Anionic surfactant could be detected with a detection limit of $1.4 \mathrm{mg} \mathrm{L}^{-1}$. The calibration curve was plotted from $5 \mathrm{mg} \mathrm{L}^{-1}$ to $500 \mathrm{mg} \mathrm{L}^{-1}$, and the error was below $5 \%$. Every sample was injected three times and the out-of-range concentrated samples were diluted with milliQ water. For the samples of permeate solution at lower concentration, a prior concentration step was used: accurate volumes of around $50 \mathrm{~mL}$ of permeate solutions were evaporated to dryness at $100{ }^{\circ} \mathrm{C}$ in glass vials. After cooling at room temperature, $2.5 \mathrm{~mL}$ of recovery solution (70\% methanol: $30 \%$ water, containing $30 \mathrm{mg} \mathrm{L}^{-1} \mathrm{NaCl}$ ) was added to the vials before vortex agitation for sample homogenisation [50]. This step enabled us to quantify SDS at concentrations above $0.25 \mathrm{mg} \mathrm{L}^{-1}$.

\subsection{RO system}

The fouling experiments of the RO membranes were performed in a laboratory set-up of SEPA CF II Membrane Element Cell from Osmonics (Fig. 3). A single piece of pre-cut flat sheet membrane with an effective filtering area of $140 \mathrm{~cm}^{2}$ was used. The width and height of the flow channel were $9.5 \mathrm{~cm}$ and $0.78 \mathrm{~mm}$, respectively. The feed stream was pumped by a high pressure pump from the feed vessel. The trans-membrane pressure was set at $30 \mathrm{bar}$, and the cross-flow velocity at $0.5 \mathrm{~m} \mathrm{~s}^{-1}$. The permeate and retentate were re-circulated to the feed vessel. The liquid temperature within the feed vessel was maintained at $25^{\circ} \mathrm{C}$ by an external thermocryostat. 


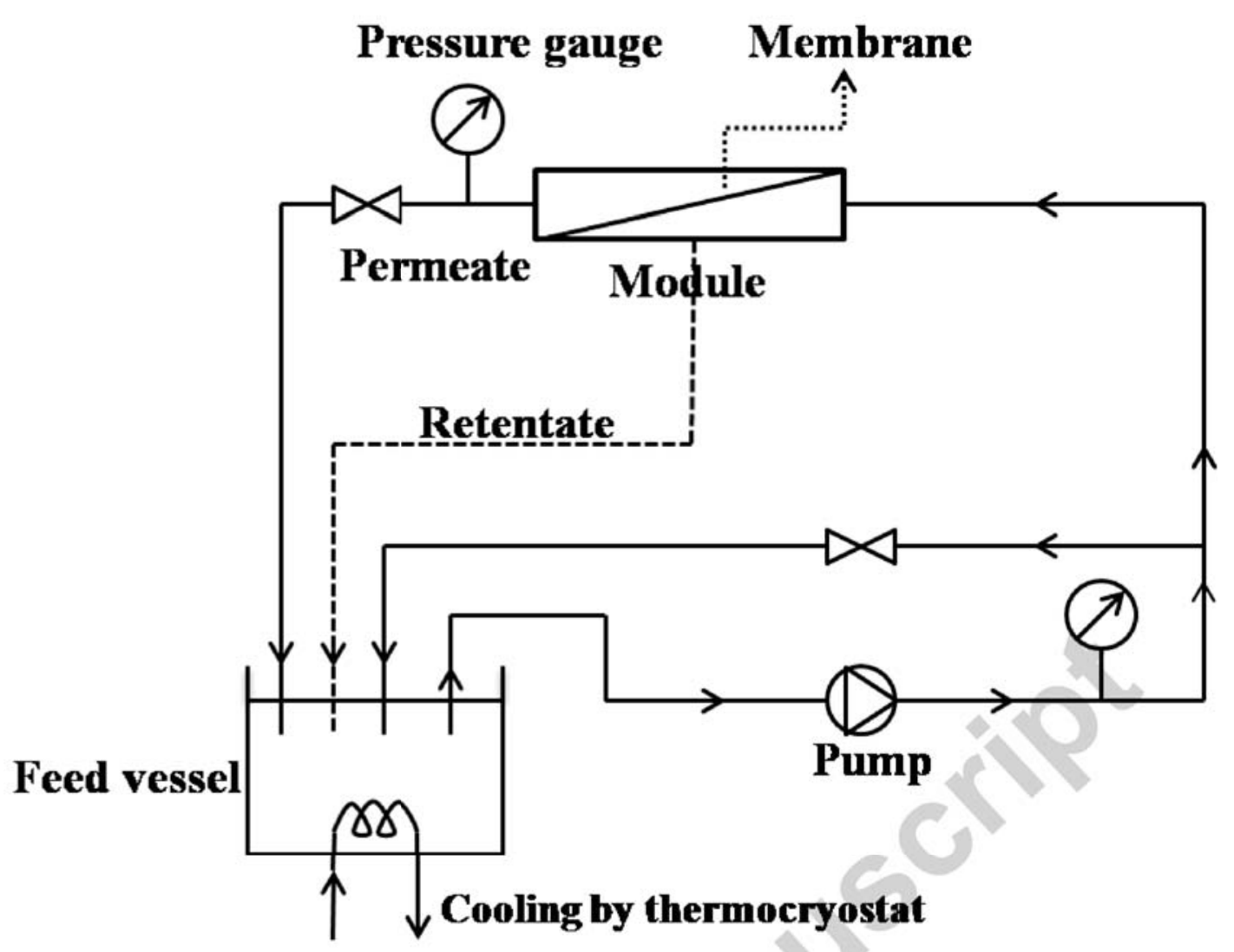

Fig. 3. Schematic representation of the SEPA CF II Membrane Element Cell

\subsection{Membrane fouling and cleaning protocols}

Each fouling experiment was conducted with a new membrane. Before the filtration of surfactant solutions, the RO membranes were installed in the filtration unit and washed with distilled water for $20 \mathrm{~min}$ at $30 \mathrm{bar}$, followed by an alkaline solution with $\mathrm{pH} 10$ for $30 \mathrm{~min}$, and then again flushed with distilled water until the $\mathrm{pH}$ returned to neutral. The integrity of the membrane was tested with $\mathrm{NaCl}$ solutions.

After the virgin membrane conditioning process, the RO system was stabilised for 20 min with distilled water at 30 bar at a cross-flow velocity of $0.5 \mathrm{~m} \mathrm{~s}^{-1}$ until a constant permeate flux was achieved. Following this step, the fouling experiments with different SDS solutions were performed for 4-6 h. The flux reached a plateau within $4 \mathrm{~h}$, but the data collection was undertaken afterwards for validation.

Experimental conditions for the fouling experiments were as follows: $4 \mathrm{~L}$ of SDS solutions at various initial concentrations ( $\mathrm{pH}$ ), from 0.8 to $80.0 \mathrm{mmol} \mathrm{L}^{-1}$ (corresponding to $0.1-10$ CMC) were filtered. Permeate, retentate and feed solution were sampled and analysed with HPLC-ELSD. The permeate flux was measured, and the accuracy was $\pm 3 \%$. If necessary, permeability values were scaled to $25{ }^{\circ} \mathrm{C}$ through the correction of viscosity. Relative flux 


\section{ACCEPTED MANUSCRIPT}

was defined as the ratio of the permeate flux to the pure water flux of the respective membrane. The osmotic pressure $\Delta \pi$ was calculated using the Van't Hoff equation, and a corrected relative flux was obtained by multiplying the relative flux by the factor $\Delta P /(\Delta P-\Delta$ $\pi)[28]$ :

$$
\Delta \pi=C \mathrm{R} T
$$

where $C$ is the concentration of solute, $\mathrm{R}$ is the gas constant, and $T$ is the absolute temperature.

The filtration performance was evaluated through permeability, normalised/relative flux, flux decline, and SDS rejection rate. After the filtration of surfactant solutions, the membranes were removed from the filtration set-up for the contact angle measurements.

The mass loss of the surfactant during filtration was estimated using a mass balance equation throughout the experiments. It contained the quantity of surfactants accumulated on the membrane surface, and adsorbed on other parts of the filtration system, with a precision of $\pm 5 \mathrm{mmol} \mathrm{m}^{-2}$.

In order to clarify the amount of SDS adsorbed on non-membrane interfaces (including plastic tubing and glass vessel) in the RO system, a small piece of plastic tubing was cut from the filtration set-up system and submerged in an SDS solution at $0.8 \mathrm{mmol} \mathrm{L}^{-1}(0.1 \mathrm{CMC})$ for $48 \mathrm{~h}$. The calculated total tubing surface area was $8.34 \mathrm{~cm}^{2}$. From the decrease in initial SDS concentration after $48 \mathrm{~h}$, the amount of adsorption of SDS per surface area of the tubing $\left(q_{\text {tub }}\right.$

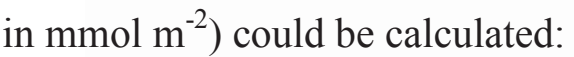

$$
q_{t u b}=\frac{C_{t=0}-C_{t=48}}{A_{t u b}} \times V_{t u b}
$$

where $C_{\mathrm{t}=0}$ and $C_{\mathrm{t}=48}\left(\mathrm{mmol} \mathrm{L}^{-1}\right)$ are SDS concentrations in the initial solution and after $48 \mathrm{~h}$, respectively; $V_{\text {tub }}(\mathrm{L})$ is the volume of the SDS solution and $A_{\text {tub }}\left(\mathrm{m}^{-2}\right)$ is the surface area of the tubing sample.

A similar method was used to obtain the adsorption amount per surface area of the glass vessel for the feed solution.

Static adsorption experiments were conducted to evaluate the maximum amount of SDS that could adsorb on and penetrated into the RO membrane, and adsorbed on the surface of internal porous support media. The internal voids are not directly accessible during filtration, only for molecules diffusing through the active surface. Before the adsorption tests, membrane samples with a nominal surface area of $9.0 \mathrm{~cm}^{2}$ were submerged in Milli-Q water for $24 \mathrm{~h}$. They were then placed separately in sealed conical flasks with $20 \mathrm{~mL}$ of SDS solution at concentrations from 0.8 to $80 \mathrm{mmol} \mathrm{L}^{-1}$. The flasks were mechanically shaken at $180 \mathrm{rpm}$ in a water bath at $25^{\circ} \mathrm{C}$ to make sure the membrane samples were fully in contact 


\section{ACCEPTED MANUSCRIPT}

with the solutions. After $24 \mathrm{~h}$, the membranes were removed and the supernatant solutions were analysed by HPLC to determine the concentrations before and after surfactant adsorption. For each surfactant solution, the average of three replicates of the static adsorption experiments was used for the calculation of adsorption quantity.

The quantity of surfactant that could adsorb on/penetrate the whole membrane, $q_{\mathrm{s}}$ (mmol $\mathrm{m}^{-2}$ ), was estimated as:

$$
q_{\mathrm{s}}=\frac{\left(C_{s, 0}-C_{s, t}\right) \times V_{s, 0}}{A_{m}}
$$

where $C_{\mathrm{s}, 0}\left(\mathrm{mmol} \mathrm{L}^{-1}\right)$ and $V_{\mathrm{s}, 0}(\mathrm{~L})$ are the initial concentration and volume of the surfactant solution in the flask, with a precision of $\pm 5 \mathrm{mmol} \mathrm{L}^{-1}$ and $\pm 5 \mathrm{~mL}$, respectively; $C_{\mathrm{s}, t}\left(\mathrm{mg} \mathrm{L}^{-1}\right)$ is the liquid concentration when the membrane is taken out of the flask (precision $\pm 5 \%$ ); and $A_{\mathrm{m}}$ $\left(\mathrm{m}^{-2}\right)$ is the geometric surface area of the membrane samples.

The accumulated SDS in the filtration module corresponding to the amount of SDS retained on the membrane, $q_{\mathrm{m}}\left(\mathrm{mmol} \mathrm{m}^{-2}\right)$, was calculated by the mass loss of SDS excluding the amount adsorbed in the non-membrane parts of the filtration system, versus the surface area of the RO membrane.

To evaluate the fouling reversibility, additional experiments were conducted for SDS solutions at $16.0 \mathrm{mmol} \mathrm{L}^{-1}$ (2 CMC). Firstly, the pristine RO membrane was subjected to SDS fouling for $4 \mathrm{~h}$. Equilibrium permeability was measured. The SDS solution was then replaced with MilliQ water without recycling of retentate or permeate for $5 \mathrm{~min}$. After water flushing, filtration was carried out for $1 \mathrm{~h}$ under the same conditions. The permeate fluxes at the beginning and end of the water rinsing procedure were recorded. The ratio of the recovered flux after rinsing to initial flux was assessed as a flux recovery rate. Finally the membrane was washed under the same conditions with a $0.5 \mathrm{~g} \mathrm{~L}^{-1} \mathrm{NaCl}$ solution containing $5 \% \mathrm{v} / \mathrm{v}$ ethanol for $10 \mathrm{~min}$ to assess the recovered flux under chemical cleaning [5].

\subsection{Contact angle measurements}

The hydrophobicity of virgin and fouled membranes was evaluated by contact angle measurements based on the method developed by Rabiller-Baudry and co-workers [51].

Before contact angle measurement, the virgin membrane samples were conditioned as follows. The fouled membranes were removed from the filtration module and gently rinsed with distilled water after fouling experiments with different SDS solutions. All the membrane samples were carefully dried in a ventilated oven at $40{ }^{\circ} \mathrm{C}$ for $48 \mathrm{~h}$ followed by at least $24 \mathrm{~h}$ in a desiccator under dynamic vacuum to prevent water re-adsorption [51]. We note that $40{ }^{\circ} \mathrm{C}$ 


\section{ACCEPTED MANUSCRIPT}

was lower than the value of maximum temperature $\left(50{ }^{\circ} \mathrm{C}\right)$ for $\mathrm{SG}$ membranes, and so all the membranes could be considered as stable during this thermal treatment.

The contact angles of SG membranes were measured on a TRACKER contact angle instrument in sessile drop mode. A droplet of liquid with a controlled volume (approximately $2.5 \mu \mathrm{L}$ ) was deposited on the RO membrane surface stuck on a glass slide, and the angle measurement was made after $80 \mathrm{~ms}$. The reason for using the contact angle at a precise short time is that the liquid drop on the membrane surface evolved when surfactant concentration was high [52].

Image analysis and contact angle computation were performed using Windrop analysis software assuming a circular profile for the droplet. To ensure accuracy, each measured contact angle was the average of at least 12 measurements at different locations, and the average value was then taken as the final contact angle result. With this well-controlled sample preparation the accuracy of the contact angle was $\pm 3^{\circ}$.

Theoretically, $\theta$ depends on the thermodynamic characteristics of both the surface and the liquid. The relationship among different parameters is given by the Dupré-Van Oss equation $[1,53]$ :

$$
(1+\cos \theta) \gamma_{l v}=2\left[\left(\gamma_{\mathrm{sv}}^{\mathrm{LW}} \times \gamma_{\mathrm{lv}}^{\mathrm{LW}}\right)^{\frac{1}{2}}+\left(\gamma_{\mathrm{sv}}^{\mathrm{A}} \times \gamma_{\mathrm{lv}}^{\mathrm{B}}\right)^{\frac{1}{2}}+\left(\gamma_{\mathrm{sv}}^{\mathrm{B}} \times \gamma_{\mathrm{lv}}^{\mathrm{A}}\right)^{\frac{1}{2}}\right]
$$

with:

$\theta \theta$ : contact angle with the liquid; s: the subscript for the dried membrane surface, $\mathrm{v}$ and 1 the subscripts for vapour and the chosen liquid, respectively; $\gamma_{\mathrm{lv}}$ and $\gamma_{\mathrm{sv}}$ (in $\mathrm{J} \mathrm{m}^{-2}$ ) are the overall surface tensions of the liquid and the membrane surface, respectively. Each of these overall values can be decomposed into different contributions, apolar $\left(\gamma_{\mathrm{lv}}^{\mathrm{LW}}\right)$ and polar $\left(\gamma^{\mathrm{A}}\right.$ : Lewis acid, $\gamma^{\mathrm{B}}$ : Lewis base).

Knowing $\gamma_{\mathrm{lv}}, \gamma_{\mathrm{lv}}^{\mathrm{LW}}, \gamma_{\mathrm{lv}}{ }^{\mathrm{A}}$ and $\gamma_{\mathrm{lv}}{ }^{\mathrm{B}}$ of three different solvents (found in the literature) and three contact angles measured with this solvent triplet on a given membrane, the values of $\gamma_{\mathrm{sv}}$, $\gamma_{\mathrm{sv}}{ }^{\mathrm{LW}}, \gamma_{\mathrm{sv}}{ }^{\mathrm{A}}$ and $\gamma_{\mathrm{sv}}{ }^{\mathrm{B}}$ can be calculated with an accuracy better than $10 \%$. The solvents used in this study were water, formamide and di-iodomethane. Their characteristics are given in Table 1.

Table 1. Surface tensions $\left(\mathrm{mJ} \mathrm{m}^{-2}\right)$ of liquids according to Van Oss [53]

\begin{tabular}{lcccc}
\hline Solvent & $\gamma_{\mathrm{lv}}$ & $\gamma_{\mathrm{lv}}{ }^{\mathrm{LW}}$ & $\gamma_{\mathrm{lv}}{ }^{\mathrm{A}}$ & ${ }{ }^{\mathrm{Bv}}{ }^{\mathrm{B}}$ \\
\hline Water & 72.8 & 21.8 & 25.5 & 25.5 \\
Formamide & 58.0 & 39.0 & 2.3 & 39.6 \\
Di-iodomethane & 50.8 & 50.8 & 0.0 & 0.0 \\
\hline
\end{tabular}




\section{Results}

First the performance of the reverse osmosis filtration (retention rate, flux decline and reversibility/cleanability of the fouling) is detailed. The accumulation of surfactant at the membrane interface during the filtration is then calculated and compared with monolayer adsorption. Lastly the impact on membrane hydrophobicity is analysed.

\subsection{Flux decline and permeability of fouled RO membranes}

The results of surfactant rejection and permeate flux of RO membranes after fouling experiments at different SDS concentrations in the equilibrium state are shown in Table 2. The surfactant rejection exceeded $99.8 \%$ in almost all the experiments over a wide range of feed concentrations. The high rejection of anionic surfactant was also found in previous studies during RO processes [4,5,29] and can be explained by two rejection mechanisms for organic molecules: electrostatic repulsion and size exclusion [32]. 


\section{ACCEPTED MANUSCRIPT}

Table 2. Rejection and flux decline during RO membrane filtration with different SDS solutions, $\Delta \mathrm{P}=$ 30 bar, $\mathrm{T}=25^{\circ} \mathrm{C}$.

\begin{tabular}{|c|c|c|c|c|c|}
\hline $\begin{array}{l}\text { Initial feed } \\
\text { concentration } \\
\left(\mathrm{mmol} \mathrm{L}^{-1}\right)\end{array}$ & $\begin{array}{c}\text { Permeate } \\
\text { concentration } \\
\left(\mathrm{mmol} \mathrm{L}^{-1}\right)\end{array}$ & $\begin{array}{c}\text { Rejection } \\
(\%)\end{array}$ & $\begin{array}{c}\text { Water flux with } \\
\text { pure water } \\
\mathrm{J}_{0} \\
\left(\mathrm{~L} \cdot \mathrm{h}^{-1} \cdot \mathrm{m}^{-2}\right)\end{array}$ & $\begin{array}{c}\text { Water flux with } \\
\text { SDS solution } \\
\mathrm{J}_{\mathrm{s}} \\
\left(\mathrm{L} \cdot \mathrm{h}^{-1} \cdot \mathrm{m}^{-2}\right)\end{array}$ & $\begin{array}{c}\text { Flux decline } \\
(\%)\end{array}$ \\
\hline 0.86 & $<8 \times 10^{-4}$ & 99.95 & 84.9 & 55.5 & 35 \\
\hline 1.53 & $9 \times 10^{-4}$ & 99.94 & 75.1 & 53.9 & 28 \\
\hline 5.13 & $8 \times 10^{-3}$ & 99.85 & 84.1 & 61.0 & 28 \\
\hline 4.71 & $2 \times 10^{-3}$ & 99.95 & 81.1 & 60.4 & 26 \\
\hline 9.21 & $5 \times 10^{-3}$ & 99.94 & 94.9 & 71.1 & 25 \\
\hline 13.15 & $8 \times 10^{-3}$ & 99.94 & 84.8 & 64.7 & 24 \\
\hline 17.82 & $1 \times 10^{-2}$ & 99.93 & 84.9 & 68.3 & 20 \\
\hline 21.14 & - & $-{ }^{\mathrm{a}}$ & 78.3 & 58.6 & 25 \\
\hline 49.14 & $5 \times 10^{-3}$ & 99.99 & 80.1 & 63.6 & 21 \\
\hline 45.90 & $4 \times 10^{-3}$ & 99.99 & 80.0 & 65.7 & 18 \\
\hline 95.05 & $6 \times 10^{-3}$ & 99.99 & 85.0 & 67.9 & 13 \\
\hline 83.30 & $5 \times 10^{-3}$ & 99.99 & 88.7 & 70.1 & 15 \\
\hline
\end{tabular}

${ }^{a}$ the permeate concentration was not measured since this was an additional experiment for the adsorption isotherm.

However, a small percentage of SDS was systematically found in the permeate, as shown in Table 2, indicating that some SDS molecules were still able to pass through the RO membrane. An equilibrium between surfactants in solution and on the RO membrane occurs through hydrophobic interactions, and adsorbed SDS molecules can undergo chain folding, by which they penetrate into the active layer of the membrane, and subsequently diffuse or are adsorbed in the active layer and in the support layer, as reported in a previous study on an RO process with perfluorooctane sulfonates (PFOS) [32]. 


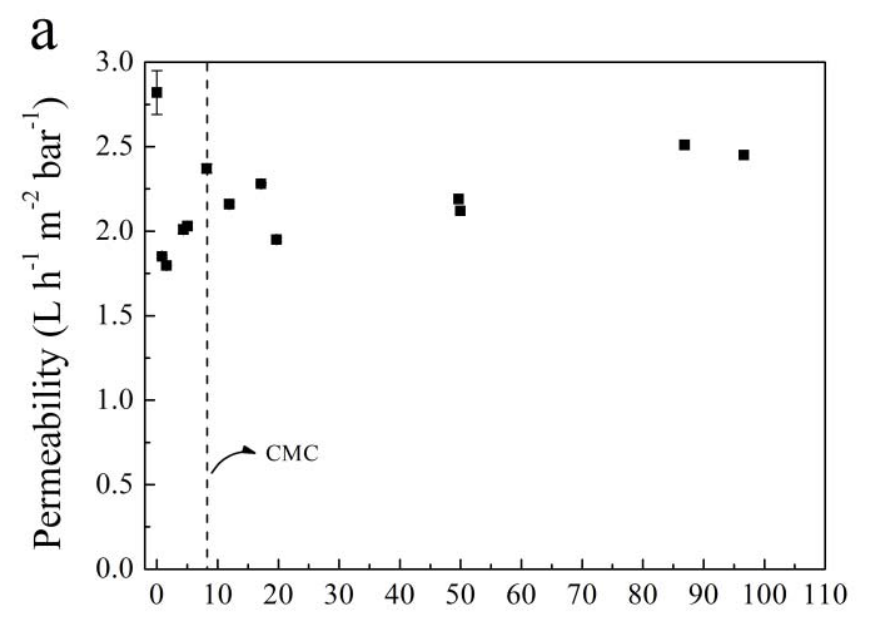

Equilibrium surfactant concentration $\left(\mathrm{mmol} \mathrm{L}^{-1}\right)$

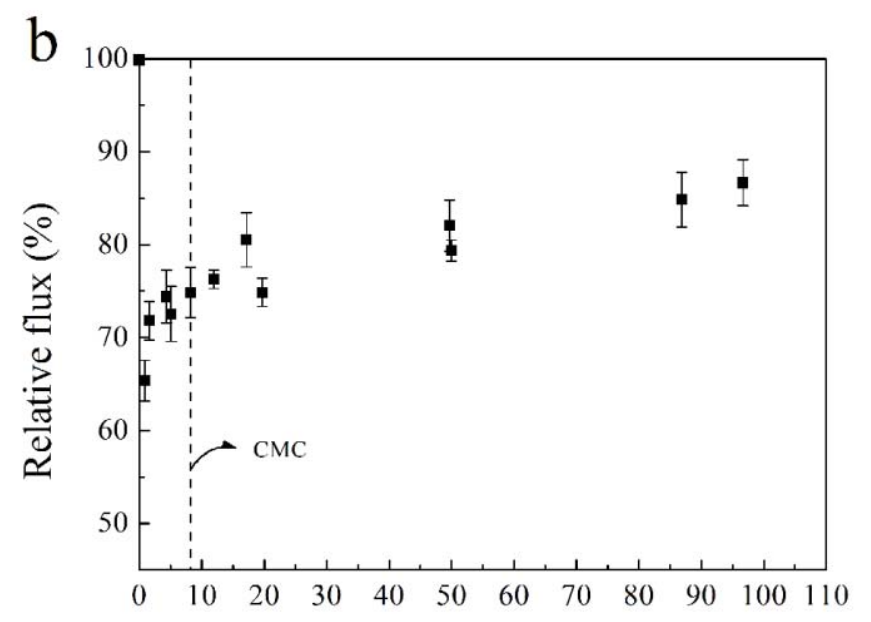

Equilibrium surfactant concentration $\left(\mathrm{mmol} \mathrm{L}^{-1}\right)$

Fig. 4. Influence of surfactant concentration on RO membrane performance: (a) equilibrium permeability and (b) relative flux of the RO membranes with SDS solutions at different concentrations. $\Delta P=30$ bar, $T=25^{\circ} \mathrm{C}$, cross-flow velocity $=0.5 \mathrm{~m} \mathrm{~s}^{-1}$.

The permeability $\left(\mathrm{L} \mathrm{h}^{-1} \mathrm{~m}^{-2}\right.$ bar $\left.{ }^{-1}\right)$ and relative flux of the RO processes for SDS solutions at equilibrium concentrations ranging from $0.84 \mathrm{mmol} \mathrm{L}^{-1}$ to $96.64 \mathrm{mmol} \mathrm{L}^{-1}$ are plotted in Fig. 4a. The equilibrium surfactant concentration is the concentration of SDS in the retentate when the flux reached a plateau. The permeability values of SDS solutions ranged from 1.80 to $2.51 \mathrm{~L} \mathrm{~h}^{-1} \mathrm{~m}^{-2}$ bar $^{-1}$, lower than the mean initial pure water permeability of $2.82 \pm 0.13 \mathrm{~L} \mathrm{~h}^{-1}$ $\mathrm{m}^{-2}$ bar $^{-1}$. 
We see in Fig. 4b that with different SDS solutions, the equilibrium relative flux of RO membrane declines to some extent, with a ratio of $13-35 \%$. The permeability and flux decline are comparable to literature values obtained by Childress et al.[33] for the filtration of 1.0 mmol L ${ }^{-1}$ SDS solution ( $\mathrm{pH}$ 6) containing $0.01 \mathrm{~mol} \mathrm{~L}^{-1} \mathrm{NaCl}$ with an FT-30 polyamide RO membrane [33]: the permeability and relative flux (corrected to $25^{\circ} \mathrm{C}$ ) in their work were 1.3 $\mathrm{L} \mathrm{h}^{-1} \mathrm{~m}^{-2}$ bar $^{-1}$ and $72 \%$, respectively.

The evolution of relative flux during RO processes (data not presented) demonstrates that the flux decline occurred in the first few minutes, and no significant flux reduction was observed thereafter. The flux decline is probably associated with fouling phenomena caused by accumulation of SDS molecules on the membrane surface, build-up of a concentration polarisation layer and/or entrapment in the polyamide layer.

As shown in Fig. 4b, the flux decline of different SDS solutions can be divided into three categories according to the equilibrium SDS concentration: (i) lower than $\mathrm{CMC} / 10$, (ii) from $\mathrm{CMC} / 10$ to $\mathrm{CMC}$, and (iii) above $\mathrm{CMC}$. The maximum flux decline was observed with $0.84 \mathrm{mmol} \mathrm{L}^{-1} \mathrm{SDS}$ solution $(\mathrm{CMC} / 10)$. This is consistent with the fouling results obtained in previous work [5]: the maximum concentrations of both main compounds were $\mathrm{CMC} / 10$ for sodium octylsulfate (Disponil SOS 842 ) and $\mathrm{CMC} / 4$ for dipropylene glycol methyl ether (Dowanol DPM), leading to the highest flux decline (80\%). The results obtained in this study also agree with those reported in the literature [28], demonstrating that for the filtration of sodium dodecyl benzene sulfonate (SDBS) at very low concentration, the relative flux of an $\mathrm{NF}$ membrane decreased with increasing surfactant concentration from $\mathrm{CMC} / 100$ to $\mathrm{CMC} / 30$. However, the relative flux increased from $65 \%$ to $75 \%$ when the SDS concentration was increased from 0.84 to $8.21 \mathrm{mmol} \mathrm{L}^{-1}$, suggesting that the membrane fouling was modified.

At higher concentrations in the range 11.92-96.64 $\mathrm{mmol} \mathrm{L}^{-1}$ above the $\mathrm{CMC}$, the relative flux still increased despite a reduced slope. It is noteworthy that a reasonable flux was still achievable at the highest SDS concentration of $96.64 \mathrm{mmol} \mathrm{L}^{-1}$.

On the other hand, results from the test of fouling reversibility by distilled water rinsing and chemical cleaning showed that RO membrane fouling was totally reversible and needed only water rinsing. After a first flushing of distilled water without recycling of retentate or permeate for $1 \mathrm{~min}$, the recovered relative flux exceeded 107\%. High recovery of organic fouling ( $>98 \%)$ was also reported on forward osmosis [54]. The reversibility of the fouling may be due to the low energy interaction between the membrane and the surfactant molecules, and the high solubility of SDS. The enhancement of the relative flux after cleaning compared with the initial flux suggests that some surfactant may stay adsorbed and improve the membrane performance by enhancing its hydrophilicity [51].

To clarify the fouling phenomena of RO membrane, it was necessary to quantify the amount of SDS accumulated on the membrane. 


\subsection{Quantification of accumulated SDS on RO membrane}

\subsubsection{Adsorption on the non-membrane parts in the RO system}

The quantity of surfactants accumulated in the RO pilot during fouling tests was calculated from the mass balance of SDS in the system. By measuring the compositions of permeate, retentate and feed solution, and comparing their sum to the initial total surfactant amount, the mass loss of SDS was obtained. The missing SDS was assumed to be adsorbed and/or accumulated on all possible interfaces in the filtration system. Apart from the RO membrane, there were other, non-membrane interfaces in contact with the surfactant solution, including (i) the glass feed vessel, (ii) the plastic (PVC, polyvinyl chloride) tubing for the recirculation of SDS solution in the filtration system, and (iii) the stainless steel pipes. The mass loss of SDS on non-membrane surfaces was estimated using the protocol described in Section 2.5.

From Equation 2, the calculated amount of SDS adsorbed on the tubing sample and the glass vessel at equilibrium with $0.8 \mathrm{mmol} \mathrm{L}^{-1} \mathrm{SDS}$ solution was $1.10 \mathrm{mmol} \mathrm{m}$ and $0.11 \mathrm{mmol} \mathrm{m}^{-2}$, respectively. The total adsorption on all the plastic materials and glass vessel in the system was calculated, and accounted for $0.14 \mathrm{mmol}$, representing $40 \%$ of the surfactant mass loss during the fouling experiment $(0.35 \mathrm{mmol})$ with $0.8 \mathrm{mmol} \mathrm{L}^{-1} \mathrm{SDS}$ solution.

To validate the accuracy of the amount of SDS adsorbed on the non-membrane interfaces, we used a metallic shim with the same surface area $\left(140 \mathrm{~cm}^{2}\right)$ to replace the RO membrane, and conducted a test of SDS adsorption in the recirculated filtration system at $16.0 \mathrm{mmol} \mathrm{L}^{-1}$. Other operating conditions for the test without RO membrane were the same as the fouling tests. Given that the flat shim showed no tendency for SDS adsorption, we can assume that all the SDS missing during this test was adsorbed on the non-membrane parts of the filtration system. We observed that the maximum mass loss of SDS during this experiment was 2.22 mmol, comprising $53 \%$ of the mass loss of SDS during the fouling experiment at the same concentration $(4.21 \mathrm{mmol})$. The surfactant adsorption on stainless steel was negligible.

The elements of the pilot where the adsorption took place except for the membrane were mainly the plastic tubing and the glass vessel, which were at atmospheric pressure (the high pressure circuit being made of stainless steel). Static adsorption at atmospheric pressure showed that above the CMC the adsorbed mass of surfactant was near-constant (not shown) on this material. In the following sections the SDS adsorption on non-membrane parts in the RO system is adjusted on the basis of $53 \%$ of mass loss during fouling experiments. 


\subsubsection{Accumulated SDS on membrane during RO filtration}

Based on the results of the previous section, the amount of SDS accumulated at the membrane surface per apparent membrane area unit $q_{\mathrm{m}}\left(\mathrm{mmol} \mathrm{m}^{-2}\right)$ is estimated at $47 \%$ of SDS mass loss in the whole system.

The equilibrium amount of accumulated surfactants (at 4-6 h) and the flux decline of the RO membrane were plotted against the equilibrium surfactant concentration in retentate as shown in Fig. 5. The results suggest that the amount of SDS accumulated during filtration with SDS equilibrium concentration can be divided into three phases. First, a rapid increase of $q_{\mathrm{m}}$ from $0.84 \mathrm{mmol} \mathrm{L}^{-1}$ to $8.21 \mathrm{mmol} \mathrm{L}^{-1}$, then a constant value from 8.21 to $49.96 \mathrm{mmol} \mathrm{L}^{-1}$., and then another increase of $q_{\mathrm{m}}$ with a reduced slope above $49.96 \mathrm{mmol} \mathrm{L}^{-1}$ when the accumulated amount reached a value of $543 \mathrm{mmol} \mathrm{m}^{-2}$ at $96.64 \mathrm{mmol} \mathrm{L}^{-1}$. Compared with the accumulated amount $q_{\mathrm{m}}$, the evolution of the flux decline exhibited a totally opposite tendency. This effect is possibly related to the modification of membrane surface properties by the accumulation of SDS.

The isotherm of the amount of accumulated SDS on a log-log scale is plotted in Fig. 6. The shape of the isotherm obtained in our experiments was slightly different from the isotherm in Fig. 2 obtained in static adsorption mode, probably because the hydrodynamic conditions of the RO process were quite different from those in static adsorption. 


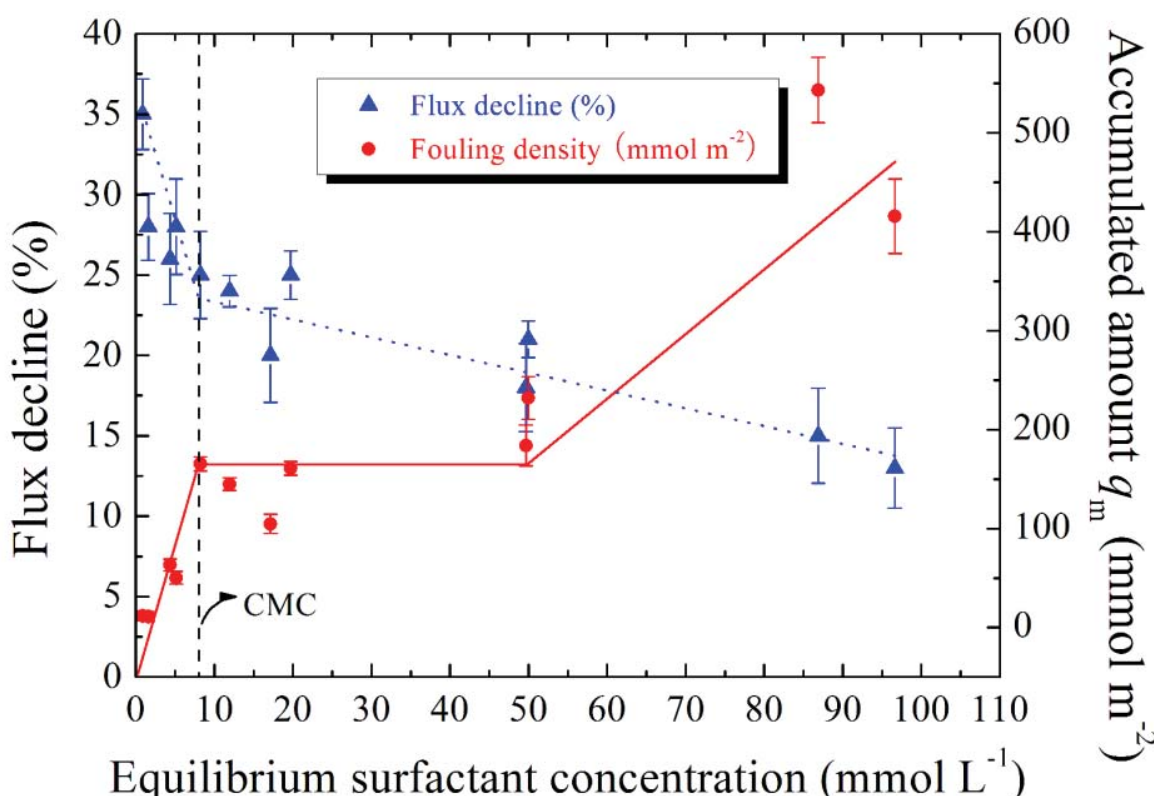

Fig. 5. Flux decline (\%) and amount of accumulated SDS $\left(\mathrm{mmol} \mathrm{m}^{-2}\right)$ versus equilibrium SDS concentration $\left(\mathrm{mmol} \mathrm{L}^{-1}\right)$ in the retentate during the RO process. $\Delta P=30$ bar, $T=25^{\circ} \mathrm{C}$.

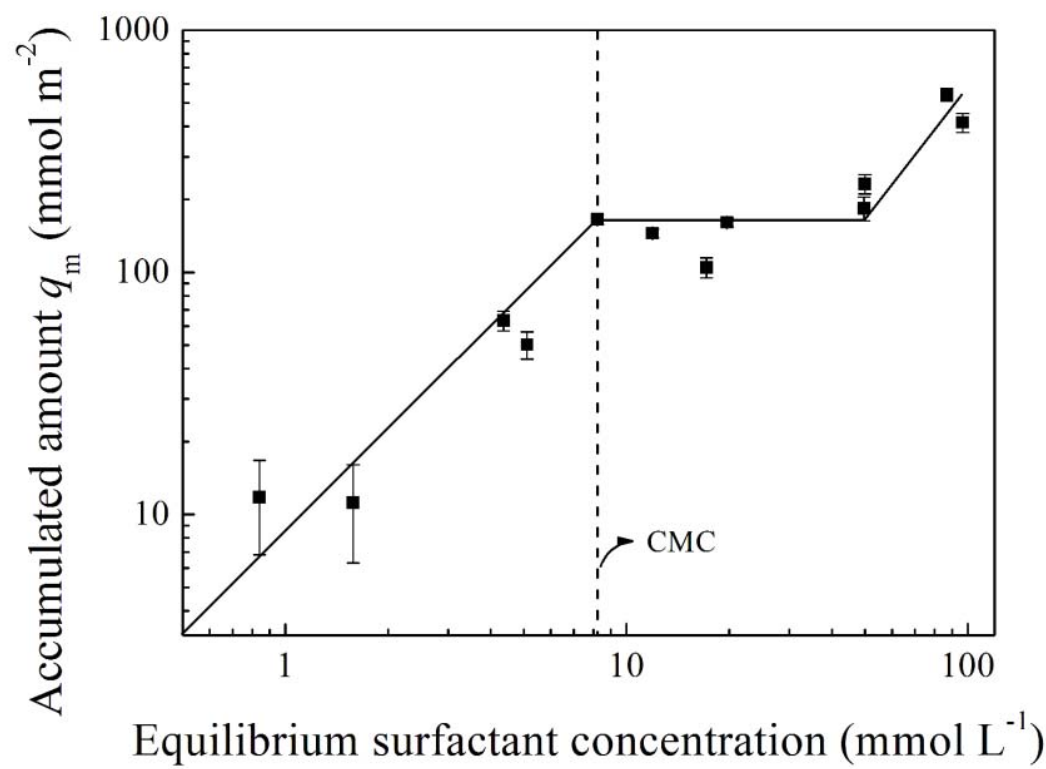

Fig. 6. Isotherm of amount of SDS accumulated on RO membrane in fouling experiments. $\Delta P=30$ bar, $T=25^{\circ} \mathrm{C}$. 


\section{ACCEPTED MANUSCRIPT}

The amount of accumulated SDS obtained in this work ranged from 11 to $543 \mathrm{mmol} \mathrm{m}^{-2}$.

As a first hypothesis, if a close-packed monolayer of SDS molecules is formed on the RO membrane active layer surface, the theoretical value of the adsorption amount can be estimated as follows: the cross sectional area of an SDS molecule at the air-water interface is $45 \AA^{2}$, and it is smaller at liquid-solid interfaces [55]. We can then expect a maximum surface excess of 4-16.6 $\mu \mathrm{mol} \mathrm{m} \mathrm{m}^{-2}, 660$ times lower than the lowest value of the accumulated amount $\left(11 \mathrm{mmol} \mathrm{m} \mathrm{m}^{-2}\right.$ at $0.84 \mathrm{mmol} \mathrm{L}^{-1}$ ) obtained from the fouling tests. Hence the amount of accumulated SDS cannot be explained simply by the formation of a monolayer on the membrane surface.

A second hypothesis is that according to the solution-diffusion mechanism, the surfactant molecules penetrate into the membrane materials and are adsorbed on the internal surfaces of the porous support layer, which represents a larger interface. To verify this, we conducted a series of static adsorption experiments with immersion of the whole membrane in the surfactant solutions in conical flasks. Results show that the adsorption amount per apparent membrane surface area $q_{\mathrm{s}}$ was $0.42 \mathrm{mmol} \mathrm{m}^{-2}$ at $0.8 \mathrm{mmol} \mathrm{L}^{-1}$ and $0.71 \mathrm{mmol} \mathrm{m}^{-2}$ at $8.0 \mathrm{mmol}$ $\mathrm{L}^{-1}$.

The whole available membrane surface in the static experiment was estimated based on MEB analysis described in reference [49]. The simplified SG membrane structure can be described as three layers as depicted in Fig. 7: the PA thin film, considered as layer 1, lies on a porous media constituted of two layers; layer 2 has a thickness $\left(e_{2}\right)$ of $40 \mu \mathrm{m}$, porosity $\left(\varepsilon_{2}\right)$ of 0.6 and contains cylindrical pores with a diameter $\left(d \mathrm{p}_{2}\right)$ of $2 \mu \mathrm{m}$; layer 3 has a thickness $\left(e_{3}\right)$ of $150 \mu \mathrm{m}$, porosity $\left(\varepsilon_{3}\right)$ of 0.6 and contains cylindrical pores with a diameter $\left(d \mathrm{p}_{3}\right)$ of $10 \mu \mathrm{m}$.

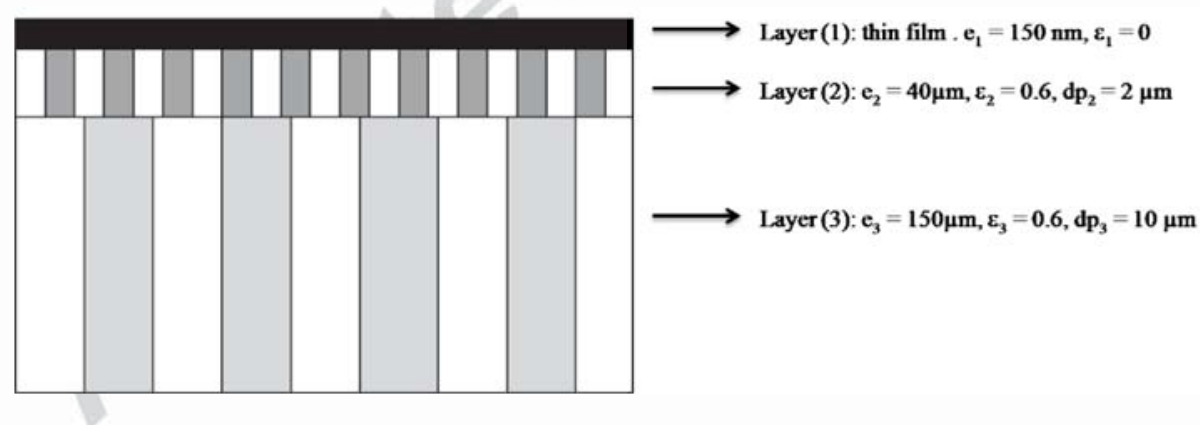

Fig. 7. Hypothesis of RO membrane structure to estimate the whole membrane surface area.

In this system the whole area can be estimated by:

$$
A_{\text {tot }}=A_{1}+A_{2}+A_{3}
$$

where $A_{1}$ : the geometric area of the thin film $\left(9 \times 10^{-4} \mathrm{~m}^{2}\right)$, assuming the internal surface of the thin film is negligible, 


\section{ACCEPTED MANUSCRIPT}

$\mathrm{A}_{2}$ : the internal area of layer 2,

$\mathrm{A}_{3}$ : the internal area of layer 3 .

The numerical application of Equation 5 gives: $A_{\text {tot }}=0.0765 \mathrm{~m}^{2}$. According to this calculation, the whole membrane area is 85 times larger than the geometric area $A_{1}$. Taking into account this whole area, the maximum surfactant adsorption calculated from the results of the static adsorption test is actually equal to $8.35 \mu \mathrm{mol} \mathrm{m}{ }^{-2}$. This value falls in the range of the above-mentioned SDS surface coverage in the case of a monolayer (3.7-16.6 $\mu \mathrm{mol} \mathrm{m} \mathrm{m}^{-2}$ ). We can consider that if the surfactant molecules manage to penetrate the PA thin film and be adsorbed on the internal surface of the porous support, then they can form a close-packed monolayer. However, this adsorption in the whole porous media would make up less than $6 \%$ of the overall accumulated amount during the fouling tests.

These calculations show that the SDS organisation at the membrane surface is more complex than a monolayer. A detailed analysis is needed to determine the structure. This will be discussed in Section 4.

\subsection{Contact angle measurements}

The contact angles of the RO membrane surface fouled by SDS solutions at $0-86.67 \mathrm{mmol} \mathrm{L}^{-1}$ are shown in Table 3, as measured with ultrapure water, formamide and di-iodomethane. The calculated surface tension $\left(\gamma_{\mathrm{s}}\right)$ and its apolar $\left(\gamma_{\mathrm{s}}^{\mathrm{LW}}\right)$ and polar $\left(\gamma_{\mathrm{s}}^{\mathrm{AB}}\right)$ contributions are listed in Table 4. 


\section{ACCEPTED MANUSCRIPT}

Table 3. Contact angles with water, formamide and di-iodomethane for virgin SG membrane and membranes after fouling tests with SDS solutions. $C_{\mathrm{SDS}}$ : concentration of SDS solution.

\begin{tabular}{ccccc}
\hline \multirow{2}{*}{ Membrane } & $C_{\mathrm{SDS}}$ & \multicolumn{3}{c}{ Contact angles $\left(^{\circ}\right)$} \\
\cline { 3 - 5 }$\left(\mathrm{mmol} \mathrm{L}^{-1}\right)$ & $\theta_{\text {water }}$ & $\theta_{\text {formamide }}$ & $\theta_{\text {di-iodomethane }}$ \\
\hline 1 & 0 & 79 & 51 & 38 \\
2 & 0.84 & 88 & 68 & 46 \\
3 & 1.57 & 81 & 52 & 41 \\
4 & 5.05 & 73 & 48 & 39 \\
5 & 4.36 & 72 & 42 & 39 \\
6 & 8.21 & 71 & 40 & 40 \\
7 & 11.92 & 74 & 43 & 37 \\
8 & 49.96 & 70 & 49 & 51 \\
9 & 49.67 & 69 & 40 & 53 \\
10 & 86.87 & 70 & 43 & 43 \\
\hline
\end{tabular}

Table 4. Surface tensions $\left(\mathrm{mJ} \mathrm{m}^{-2}\right)$ of SG membranes with SDS solutions at different concentrations (inferred from contact angles listed in Table 3, calculation based on Equation 4. $\Gamma_{\mathrm{s}}$ : surface tension of SG membrane.

\begin{tabular}{cccccccc}
\hline Membrane & $\begin{array}{c}C_{\mathrm{SDS}} \\
\left(\mathrm{mmol} \mathrm{L}^{-1}\right)\end{array}$ & $\gamma_{\mathrm{s}}^{\mathrm{LW}}$ & $\gamma_{\mathrm{s}}^{\mathrm{A}}$ & $\gamma_{\mathrm{s}}^{\mathrm{B}}$ & $\gamma_{\mathrm{s}}^{\mathrm{AB}}$ & $\Gamma_{\mathrm{s}}$ \\
\hline 1 & 0 & 39.3 & 0.7 & 3.8 & 3.2 & 42.5 \\
2 & 1.57 & 39.1 & 0.7 & 3.0 & 2.9 & 42.1 \\
3 & 5.05 & 40.1 & 0.5 & 6.5 & 3.6 & 43.6 \\
4 & 4.36 & 40.0 & 1.4 & 5.7 & 5.6 & 45.6 \\
5 & 8.21 & 39.7 & 1.8 & 5.7 & 6.3 & 46.0 \\
6 & 11.92 & 41.1 & 1.2 & 5.2 & 4.9 & 46.0 \\
7 & 49.67 & 32.4 & 3.3 & 7.4 & 9.8 & 42.3 \\
8 & 86.87 & 38.2 & 1.4 & 7.7 & 6.5 & 44.7 \\
\hline
\end{tabular}




\section{ACCEPTED MANUSCRIPT}

The contact angles in Table 3 indicate that the virgin membrane is hydrophobic, with a contact angle of $79^{\circ}$ with ultrapure water. The value obtained is higher than the literature value of $69.3^{\circ}$ for the same membrane [49]. The difference may be due to different operating conditions, such as temperature, humidity, etc. After filtration of $0.84 \mathrm{mmol} \mathrm{L}^{-1} \mathrm{SDS}$ solution without rinsing, the contact angle of the $\mathrm{RO}$ membrane with water increased to $88^{\circ}$, indicating that the membrane surface became more hydrophobic after the contact of SDS solution. This was concomitant with the relative flux decline described in Section 3.1.

The contact angle with water then decreased to $71^{\circ}$ with increasing surfactant concentration to $8.21 \mathrm{mmol} \mathrm{L}^{-1}$, showing an enhancement in the hydrophilicity of the SG membranes. The relative flux also rose. At higher concentrations, the contact angles remained constant at around $71^{\circ}$ and relative flux variation was small. According to the literature, surfactant adsorption on solid substrates can modify surface hydrophobicity, depending on the orientation of adsorbed surfactant molecules [56].

The electron-donor surface tension parameter $\left(\gamma_{\mathrm{s}}^{\mathrm{B}}\right)$ is a fairly good semiquantitative indicator of the degree of the polar character of a surface. When SDS molecules are adsorbed on the membrane surface, their sulfate ions contribute to the Lewis base $\left(\gamma_{\mathrm{s}}{ }^{\mathrm{B}}\right)$. From Table 4 , a slight increase in $\gamma_{\mathrm{s}}^{\mathrm{B}}$ and in the ratio of $\gamma_{\mathrm{s}}^{\mathrm{B}} / \gamma_{\mathrm{s}}^{\mathrm{LW}}$ occurred on increasing the aqueous surfactant concentration from 1.57 to $86.87 \mathrm{mmol} \mathrm{L}^{-1}$. The increase in the electron-donicity parameter $\gamma_{\mathrm{s}}^{\mathrm{B}}$ and the ratio of $\gamma_{\mathrm{s}}{ }^{\mathrm{B}} / \gamma_{\mathrm{s}}^{\mathrm{LW}}$ suggests an enhancement of membrane hydrophilicity. Hence we can conclude that the adsorption of surfactant anions as electron donors increased the charge of negatively charged RO membrane surface with the head on top of the surface, thus rendering them more hydrophilic.

These phenomena are consistent with published observations with zeta potential measurements. Previous work revealed that the zeta potentials of RO membranes in the presence of SDS were much more negative than with no SDS [33]. The reason was that surfactant molecules were readily adsorbed on the membrane surface, and their negatively-charged functional head groups dominated the membrane surface charge.

\section{Discussion}

In this part we compare the present results with those of the literature. A proposed organisation of the surfactants at the membrane surface is then described, deduced from the SDS phase diagram and linked to the hydrophobicity measurements, to explain the flux decline.

Quantities of ionic surfactants adsorbed on the RO membrane surface or in the pilot during the RO process has been reported in previous approaches $[5,28,30]$. The experimental values of the mass loss of SDS accumulated in the RO pilot and static adsorption of SDS in the 


\section{ACCEPTED MANUSCRIPT}

present work can be compared with literature values if we plot the adsorption density versus the surfactant concentrations in CMC units, as shown in Fig. 8. The types of surfactants, the membranes and the operating conditions of these adsorption experiments are summarised in Table 5. Two were in filtration mode, and the other was conducted in static adsorption mode. In our previous work we observed an adsorption density of $210-263 \mathrm{mmol} \mathrm{m}^{-2}$ for anionic surfactant Disponil SOS 842 (formula: $\mathrm{C}_{8} \mathrm{H}_{17} \mathrm{SO}_{4} \mathrm{Na}$ ) on a thin-film polyamide CSM-RE2540-FE reverse osmosis membrane under experimental conditions similar to those here [5]. Hinke et al. [30] found that the amount of anionic surfactant FT 248 (formula: $\left.\mathrm{C}_{8} \mathrm{~F}_{17} \mathrm{SO}_{3} \mathrm{~N}\left(\mathrm{C}_{2} \mathrm{H}_{5}\right)_{4}\right)$ adsorbed on a CA-10 membrane was $1.59 \mathrm{mmol} \mathrm{m}^{-2}$ at $10 \mathrm{bar}$, and it increased to $6.68 \mathrm{mmol} \mathrm{m}^{-2}$ at 40 bar. However, the amounts of surfactants on non-membrane materials were not excluded in either investigation. Another group demonstrated that SDBS (formula: $\mathrm{C}_{12} \mathrm{H}_{25} \mathrm{C}_{6} \mathrm{H}_{4} \mathrm{SO}_{3} \mathrm{Na}$ ) was adsorbed on an $\mathrm{NF}$ polyamide membrane with an adsorption density of $2.6 \mathrm{mmol} \mathrm{m}^{-2}$ during static adsorption [28], of the same order magnitude as our results of $0.71 \mathrm{mmol} \mathrm{m}^{-2}$. The results obtained in the present work are of the same order of magnitude as those described in earlier papers.

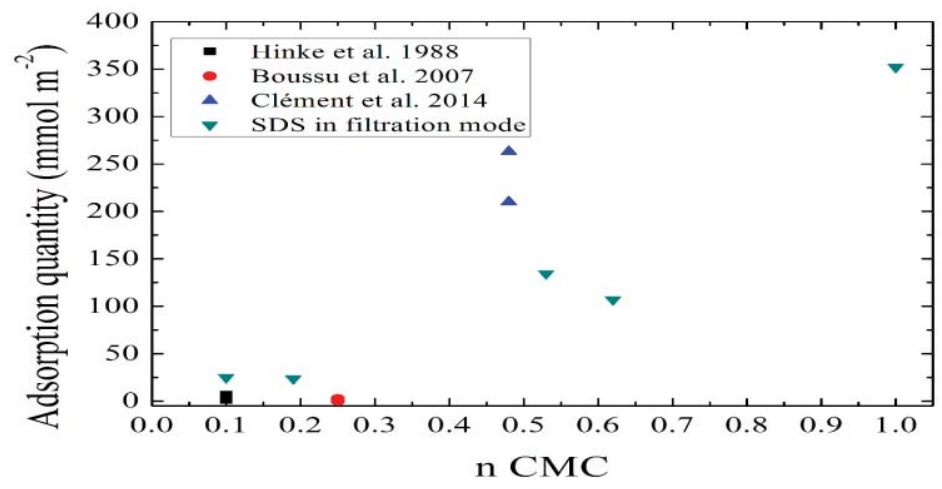

Fig. 8. Adsorption quantity $\left(\mathrm{mmol} \mathrm{m}^{-2}\right)$ versus equilibrium surfactant concentration in retentate (in the form of $n \mathrm{CMC}$ ) in the system containing surfactant solution and membrane, compared with literature: $\boldsymbol{\nabla} \mathrm{RO}$ process of SDS solution at $0.84(n=0.1)$ to $8.21(n=1) \mathrm{mmol} \mathrm{L}^{-1}$ with a polyamide SG membrane at 30 bar; $\mathrm{RO}$ filtration of surfactant FT 248 at $0.11 \mathrm{mmol} \mathrm{L}^{-1}$ with membrane CA-10, $P$ $=10$ and 40 bar, in the work of Hinke et al. [30]; OStatic adsorption of surfactant SDBS at 1.72 mmol L ${ }^{-1}$ with NF membranes (NF270, Desa151HL, NTR745 and NFPES10), in the work of Boussu et al. [28]; $\boldsymbol{\Delta}$ Data from the work of Clément et al. [5], RO filtration of surfactant SOS at 64 to $69 \mathrm{mmol}$ $\mathrm{L}^{-1}$ with CSM-RE2540-FE membrane, $P=30$ bar. The result of maximum adsorption amount of SDS in static adsorption mode was $0.71 \mathrm{mmol} \mathrm{m}^{-2}$ at $8.0 \mathrm{mmol} \mathrm{L}^{-1}(n=1)$, not visually observable in the figure. 


\section{ACCEPTED MANUSCRIPT}

Table 5. Basic properties of some surfactants and literature values of their adsorption on membranes

\begin{tabular}{ccccc}
\hline Reference & $\begin{array}{c}\text { Hinke et al. 1988 } \\
{[30]}\end{array}$ & $\begin{array}{c}\text { Boussu et al. 2007 } \\
{[28]}\end{array}$ & Clément et al. 2014 [5] & This work \\
\hline \multicolumn{5}{c}{ Basic properties of surfactants } \\
\hline Name & FT 248 & SDBS & SOS & SDS \\
\hline Formula & $\mathrm{C}_{8} \mathrm{~F}_{17} \mathrm{SO}_{3} \mathrm{~N}_{\left(\mathrm{C}_{2} \mathrm{H}_{5}\right)_{4}}$ & $\mathrm{C}_{12} \mathrm{H}_{25} \mathrm{C}_{6} \mathrm{H}_{4} \mathrm{SO}_{3} \mathrm{Na}$ & $\mathrm{C}_{8} \mathrm{H}_{17} \mathrm{SO}_{4} \mathrm{Na}$ & $\mathrm{C}_{12} \mathrm{H}_{25} \mathrm{SO}_{4} \mathrm{Na}$ \\
\hline $\begin{array}{c}\mathrm{CMC} \\
(\mathrm{mmol} \mathrm{L}\end{array}$ & 0.8 to 1.1 & 6.67 & 140 & 8 \\
\hline
\end{tabular}

\begin{tabular}{|c|c|c|c|c|}
\hline \multicolumn{5}{|c|}{ Adsorption on membranes } \\
\hline Mode & $\begin{array}{l}\text { Adsorption during } \\
\text { filtration }\end{array}$ & Static adsorption & $\begin{array}{l}\text { Adsorption during } \\
\quad \text { filtration }\end{array}$ & $\begin{array}{l}\text { Adsorption during } \\
\text { filtration }\end{array}$ \\
\hline $\begin{array}{l}\text { Type of } \\
\text { membrane }\end{array}$ & $\begin{array}{c}\text { RO } \\
\text { Cellulose acetate } \\
(\mathrm{CA}-10)\end{array}$ & $\begin{array}{c}\text { NF } \\
\text { PA and PES } \\
\text { (NF270, Desal51HL, } \\
\text { NTR7450, FPES10) }\end{array}$ & $\begin{array}{c}\text { RO } \\
\text { polyamide } \\
\text { (CSM RE2540-FE) }\end{array}$ & $\begin{array}{c}\mathrm{RO} \\
\text { polyamide } \\
(\mathrm{SG})\end{array}$ \\
\hline $\mathrm{T}\left({ }^{\circ} \mathrm{C}\right)$ & 20 & 20 & 30 & 25 \\
\hline $\mathrm{pH}$ & No adjustment & 6 & No adjustment & 6 \\
\hline $\begin{array}{c}\text { Equilibrium } \\
\text { concentration } \\
\text { with } \\
\text { membrane } \\
\left(\mathrm{mmol} \mathrm{L}^{-1}\right) \\
\end{array}$ & $\begin{array}{c}0.11 \text { (with } 0.005 \mathrm{M} \\
\mathrm{NaCl} \text { ) }\end{array}$ & 1.72 & 64 to 69 & 0.84 to 96.64 \\
\hline $\begin{array}{l}\text { Adsorption } \\
\text { quantity } \\
\left(\mathrm{mmol} \mathrm{m}^{-2}\right)\end{array}$ & $\begin{array}{c}1.59 \text { at } 10 \text { bar; } \\
6.68 \text { at } 40 \text { bar } \\
\text { (in the filtration } \\
\text { pilot) }\end{array}$ & $\begin{array}{l}0 \text { for NF270; } \\
1.5 \text { for Desal51HL; } \\
2.6 \text { for NTR7450 and } \\
\text { NFPES10 } \\
\text { (on the membrane) }\end{array}$ & $\begin{array}{l}210 \text { to } 263 \text { at } 30 \text { bar } \\
\text { (in the filtration pilot) }\end{array}$ & $\begin{array}{l}23 \text { to } 1157 \text { at } 30 \\
\text { bar } \\
\text { (in the filtration } \\
\text { pilot) }\end{array}$ \\
\hline Flux decline & $\begin{array}{l}10 \% \text { at } 10 \text { bar; } \\
20 \% \text { at } 20 \text { bar; } \\
65 \% \text { at } 40 \text { bar }\end{array}$ & $\begin{array}{l}\text { At } 0.11 \mathrm{mmol} \mathrm{L}^{-1} \text {, } \\
5 \% \text { for } \mathrm{NF} 270 \text {; } \\
13 \% \text { for Desal } 51 \mathrm{HL} \text {; } \\
9 \% \text { for NTR } 7450 \text { and } \\
38 \% \text { for NFPES } 10\end{array}$ & 75 to $80 \%$ & 20 to $35 \%$ \\
\hline
\end{tabular}




\section{ACCEPTED MANUSCRIPT}

In Section 3.2 we demonstrated that the matter accumulated on the membrane cannot be interpreted as a monolayer of surfactant adsorbed at the solid-liquid interface. In the following section, different structures are proposed. According to the concentration polarisation (CP) theory, the concentration of SDS in the vicinity of the RO membrane surface is much higher than that of the feed solution during filtration. In this work, a simplified model was introduced to predict the concentration polarisation. Fig. 9 depicts the polarisation layer. Since there is no detailed description of the CP layer, the first hypothesis is that the excess of surfactant is accumulated in half of the flow channel, only one membrane being in the module. The thickness was assumed to be roughly half of the flow channel $(0.79 \mathrm{~mm})$. The mean concentration $C_{\mathrm{m}}$ in this layer was then calculated. It was taken as composed of the amount in the retentate plus that accumulated on the membrane (Equation 6). The results of $C_{\mathrm{m}}$ calculations are given in Table 6 . The concentration of the retentate and the flux decline of the fouling tests versus the concentration in CP layer are plotted in Fig. 10.

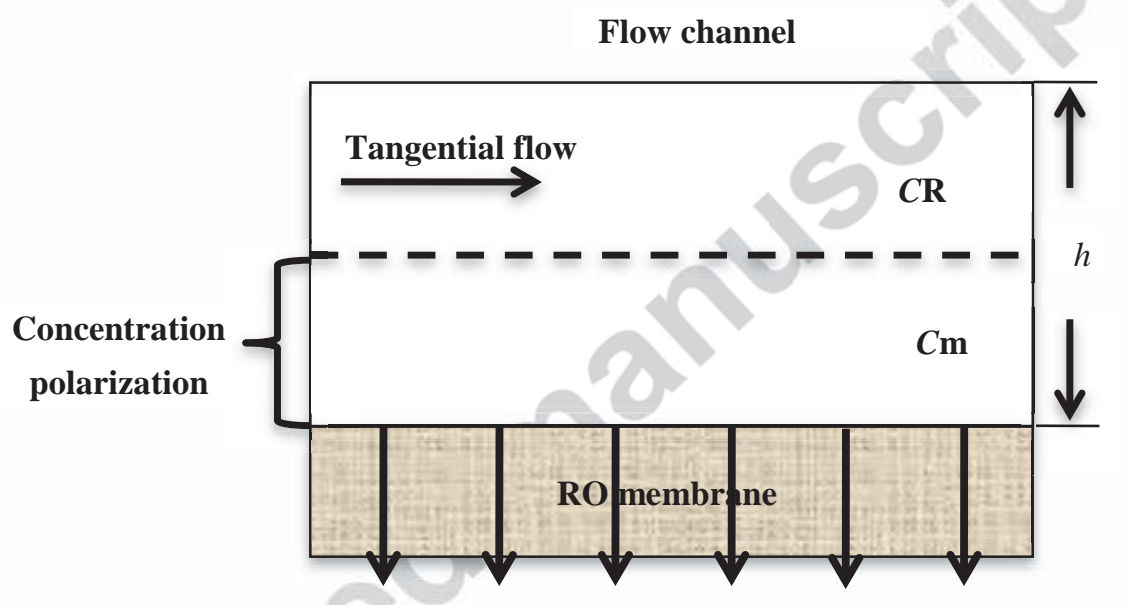

Fig. 9. Diagram of the concentration polarisation (CP) layer in the flow channel in contact with the RO membrane during fouling tests. $C_{\mathrm{R}}$ : SDS concentration of the retentate; $C_{\mathrm{m}}$ : SDS concentration in the CP layer; $h$ : height of the flow channel, $0.7874 \mathrm{~mm}$.

$$
C_{m}=C_{R}+2 q_{m} / h
$$

To clarify the possible structure in the condensed region, the phase diagram calculated from Fig. 1 is added to Fig. 10. The proposed structures are depicted in Fig. 11.

In the concentration region of $C_{\mathrm{R}}<\mathrm{CMC}$, from $C_{\mathrm{R}}=0.84 \mathrm{mmol} \mathrm{L}^{-1}$ to $C_{\mathrm{R}}=8.53 \mathrm{mmol} \mathrm{L}^{-1}$, we note coherent changes in the membrane surface properties and the concentrated multi-layer structures in the CP layer. When $C_{\mathrm{R}}=0.84 \mathrm{mmol} \mathrm{L}^{-1}$, according to flux and contact angle measurements, the organisation of the surfactant at the membrane interface led to high flux decline and a membrane that was less hydrophilic than the virgin membrane. From the phase 


\section{ACCEPTED MANUSCRIPT}

diagram in Fig. 10, the liquid phase in CP was in a micellar state, but the mean CP concentration was 37 times higher than $C_{R}$. At this concentration the surfactant could be organized in a dense structure adsorbed on the solid, in equilibrium with the micellar solution, with a part of the hydrophobic tails towards the solution (cf. multi-layers, Fig. 11 (1)).

From $C_{\mathrm{R}}=0.84$ to $C_{\mathrm{R}}=4.67 \mathrm{mmol} \mathrm{L}^{-1}$, the permeability and hydrophilicity of RO membrane were markedly improved, whereas the concentration of $\mathrm{CP}$ rose to $165 \mathrm{mmol} \mathrm{L}^{-1}$, showing a strong change in the structure of the fouling. The liquid was still in a micellar phase. The dense layer could be thicker, but the hydrophobicity could be modified by the addition of surfactants with the head towards the solution.

Between $C_{\mathrm{R}}=4.67$ and $11.92 \mathrm{mmol} \mathrm{L}^{-1}$, the concentration in $\mathrm{CP}$ increased sharply, but the retentate concentration exiting from the pipe showed no significant increase and stayed around the CMC. $\mathrm{d} C_{\mathrm{R}} / \mathrm{d} C_{\mathrm{m}}=0.027$. The flux decline and contact angles were near-stable. One major structure composed of accumulated micelles could form the polarisation layer and/or the adsorbed structures (see Fig. 11 (2)). The thickness of this porous cake could increase but with little influence on the flux because of the high porosity and the hydrophilicity of the micelles with polar head towards the solution.

Table 6. Summary of the concentrations of SDS in the concentration polarization layer, $C_{\mathrm{m}}$, during fouling experiments, calculated from Equation 6.

\begin{tabular}{ccc}
$C_{\mathrm{R}}\left(\mathrm{mmol} \mathrm{L}^{-1}\right)$ & $q_{\mathrm{m}}\left(\mathrm{mmol} \mathrm{m}^{-2}\right)$ & $C_{\mathrm{m}}\left(\mathrm{mmol} \mathrm{L}^{-1}\right)$ \\
\hline 0 & 0 & 0 \\
0.84 & 12 & 31 \\
1.58 & 11 & 30 \\
4.67 & 63 & 165 \\
8.53 & 165 & 429 \\
11.92 & 145 & 380 \\
52.23 & 232 & 641 \\
100.68 & 416 & 1156 \\
89.27 & 543 & 1469 \\
\hline
\end{tabular}




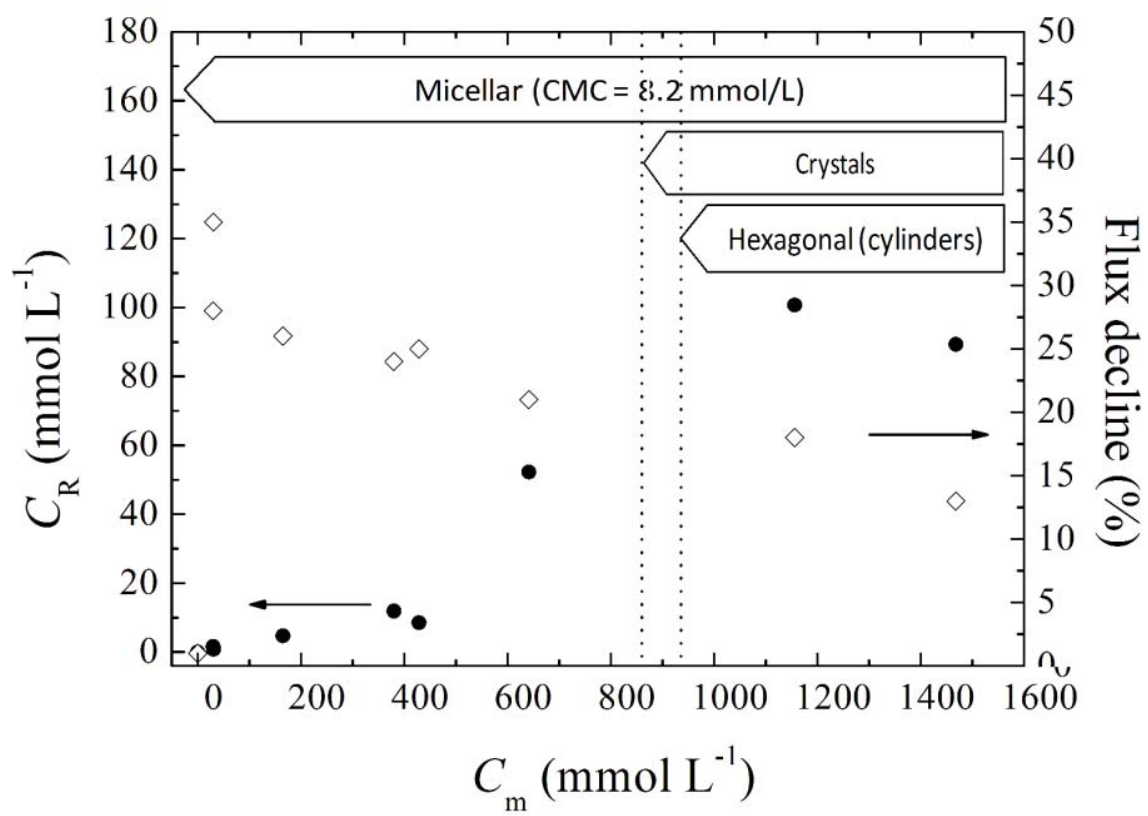

Fig. 10. Retentate concentration and flux decline as a function of $C_{\mathrm{m}}$. Phase diagram of SDS $\left(25^{\circ} \mathrm{C}\right)$ calculated from Fig. 1 is indicated. $C_{\mathrm{R}}$ : SDS concentration of the retentate; $C_{\mathrm{m}}$ : SDS concentration in the CP layer, calculated from the fouling tests.

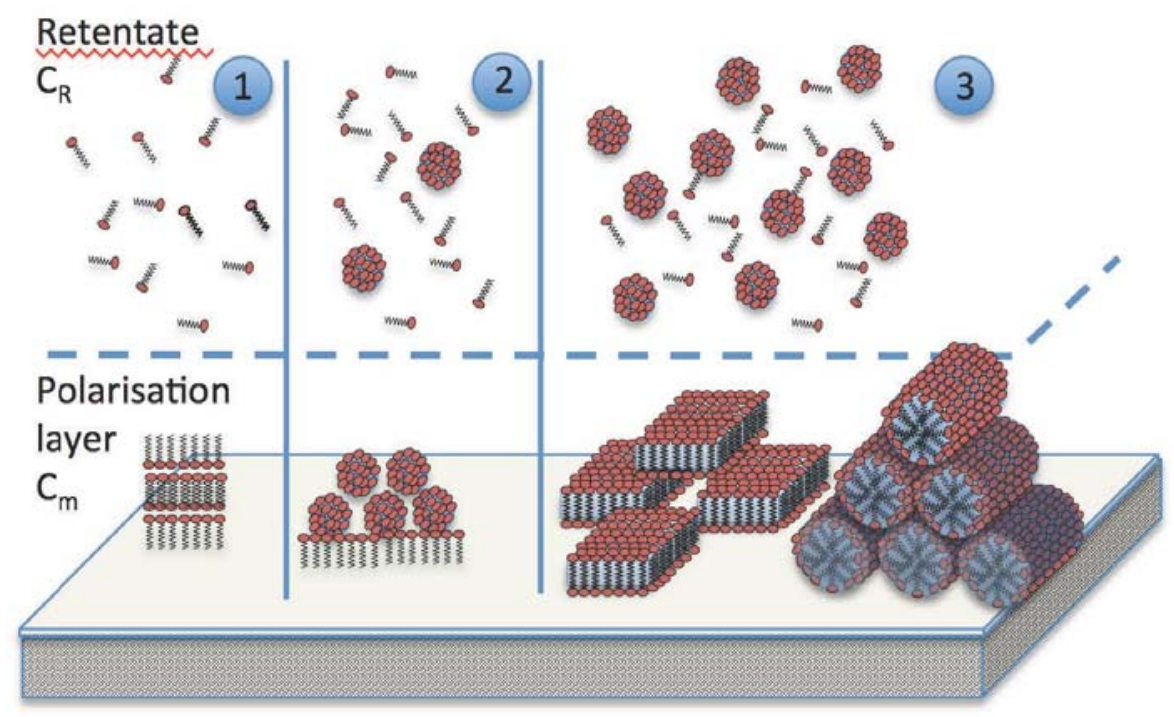

Fig. 11. Depiction of the organisation of surfactant in the polarisation layer during RO filtration versus the concentration in the retentate. 
Between $C_{\mathrm{R}}=11.92$ and $100.68 \mathrm{mmol} \mathrm{L}^{-1}$, a second strong change in the structure occurred. The concentration in the retentate exiting from the pipe rose from $\mathrm{CMC}$ to $10 \mathrm{CMC}$, and the accumulated amount $q_{\mathrm{m}}$ increased from 145 to $543 \mathrm{mmol} \mathrm{m}^{-2} . \mathrm{d} C_{\mathrm{R}} / \mathrm{d} C_{\mathrm{m}}=0.176,6.5$ times the previous value. This indicated a change in the equilibrium. The $\mathrm{CP}$ concentration rose from 380 to $1469 \mathrm{mmol} \mathrm{L}^{-1}$ corresponding to 12.3 to $73.5 \mathrm{wt} \%$. According to the phase diagram in the same interval of concentration, a crystal mesophase appeared (see Fig. 11 (3)). Depending on the local temperature, hexagonal structures could also be created, with cylinders in a hexagonal lattice. In the same interval, $\gamma_{\mathrm{s}}^{\mathrm{LW}}$ decreased drastically, whereas $\gamma_{\mathrm{s}}^{\mathrm{B}}$ increased. However, this phenomenon had little influence on the permeability. We can suppose that the rise in hydrophilicity was offset by the rise in structure density, and a reorganised structure at equilibrium with a more concentrated aqueous phase appeared.

For $C_{\mathrm{R}}$ above $52.23 \mathrm{mmol} \mathrm{L}^{-1}, q_{\mathrm{m}}$ increased, the thickness or density of this new stable structure could rise leading to the decrease in permeability, but the $C_{\mathrm{R}}$ at equilibrium and the hydrophilicity did not change drastically.

These tentative interpretations fit results obtained from macroscopic measurements. However, the elucidation of surfactant organisation on the membrane surface calls for further detailed investigation beyond the scope of the present work. Experimental methods such as small-angle X-ray scattering (SAXS) are potential techniques to investigate the phase behaviour of surfactants [57-60].

\section{Conclusion}

We investigated the effects of surfactants on RO membrane fouling. The results obtained from the membrane separation properties confirm that the RO process is very efficient for the removal of surfactants, more than $99.8 \%$ of the surfactants being rejected by the membrane over the whole concentration range (below, equivalent and above the $\mathrm{CMC}$ ) in this work. However, membrane fouling during filtration caused by surfactant accumulation adversely affected the membrane performance and its surface characteristics. The relative fluxes of surfactant solutions were quickly and significantly reduced compared with pure water. However, the membrane fouling was completely reversible by rinsing with distilled water. The quantification of the accumulated matter by comparison with the SDS phase diagram, contact angle measurements and relative flux analyses demonstrates that the large amount of surfactant accumulated on the membrane is not a monolayer, but is organised in different complex structures depending on the concentration.

However, the hypothesis of solubilisation of SDS in the polymer matrix and the organisation of the surfactants in complicated surface structures could not be experimentally verified in this work for lack of a precise observation method to study this microscopic organisation. A 
powerful experimental method such as SAXS or coarse-grained molecular simulation could be used to elucidate the organisation of surfactants involved in membrane processes.

\section{Acknowledgments}

The authors thank Anthony Szymczyk and Yamina Hanafi for the streaming current measurements (Institut des Sciences Chimiques de Rennes-UMR CNRS 6226, Université Rennes 1, Campus de Beaulieu, 263 avenue du Général-Leclerc, 35000 Rennes, France). We thank the China Scholarship Council for supporting Z. Mai with a PhD grant.

\section{References}

[1] M.J. Rosen, Surfactants and Interfacial Phenomena, 3rd Edition., John Wiley \& Sons, 2004.

[2] M.J. Scott, M.N. Jones, The biodegradation of surfactants in the environment, Biochim. Biophys. Acta. 1508 (2000) 235-251.

[3] K. Majewska-Nowak, I. Kowalska, M. Kabsch-Korbutowicz, Ultrafiltration of SDS solutions using polymeric membranes, Desalination. 184 (2005) 415-422.

[4] C. Baudequin, E. Couallier, M. Rakib, I. Deguerry, R. Severac, M. Pabon, Purification of firefighting water containing a fluorinated surfactant by reverse osmosis coupled to electrocoagulation-filtration, Sep. Purif. Technol. 76 (2011) 275-282.

[5] C. Baudequin, Z. Mai, M. Rakib, I. Deguerry, R. Severac, M. Pabon, et al., Removal of fluorinated surfactants by reverse osmosis - Role of surfactants in membrane fouling, J. Memb. Sci. 458 (2014) 111-119.

[6] C.Y. Tang, T.H. Chong, A.G. Fane, Colloidal interactions and fouling of NF and RO membranes: a review., Adv. Colloid Interface Sci. 164 (2011) 126-143.

[7] J. Hermia, Constant pressure blocking filtration laws: Application to power-law non-newtonian fluids, Trans. Inst. Chem. Eng. 60 (1982) 183-187.

[8] W. Guo, H.-H. Ngo, J. Li, A mini-review on membrane fouling, Bioresour. Technol. 122 (2012) 27-34. 


\section{ACCEPTED MANUSCRIPT}

[9] M.F.A. Goosen, S.S. Sablani, H. Al-Hinai, S. Al-Obeidani, R. Al-Belushi, D. Jackson, Fouling of reverse osmosis and ultrafiltration membranes: a critical review, Sep. Sci. Technol. 39 (2004) 2261-2298.

[10] S.S. Sablani, M.F.A. Goosena, R. Al-Belushi, M. Wilf, Concentration polarization in ultrafiltration and reverse osmosis: a critical review, Desalination. 141 (2001) 269-289.

[11] T. Srisukphun, C. Chiemchaisri, T. Urase, K. Yamamoto, Experimentation and modeling of foulant interaction and reverse osmosis membrane fouling during textile wastewater reclamation, Sep. Purif. Technol. 68 (2009) 37-49.

[12] H. Byhlin, A. Jönsson, Influence of adsorption and concentration polarisation on membrane performance during ultrafiltration of a non-ionic surfactant, Desalination. 151 (2003) 21-31.

[13] Z. Mai, E. Couallier, M. Rakib, B. Rousseau, Parameterization of a mesoscopic model for the self-assembly of linear sodium alkyl sulfates., J. Chem. Phys. 140 (2014) 204902.

[14] P. Kékicheff, C. Grabielle-Madelmont, M. Ollivon, Phase Diagram of Sodium Dodecyl Sulfate-Water System: 1. A Calorimetric Study, J. Colloid Interface Sci. 131 (1989) $112-132$.

[15] P. Kékicheff, Phase Diagram of Sodium Dodecyl Sulfate-Water System: 2. Complementary Isoplethal and Isothermal Phase Studies, J. Colloid Interface Sci. 131 (1989) 133-152.

[16] G.J.T. Tiddy, Surfactant-Water Liquid Crystal Phases, Phys. Reports (Review Sect. Phys. Lett. 57 (1980) 1-46.

[17] H.C. Schniepp, H.C. Shum, D. a Saville, I. a Aksay, Surfactant aggregates at rough solid-liquid interfaces., J. Phys. Chem. B. 111 (2007) 8708-8712.

[18] L.K. Koopal, E.M. Lee, M.R. Bohmer, Adsorption of Cationic and Anionic Surfactants on Charged Metal Oxide Surfaces, J. Colloid Interface Sci. 170 (1995) 85-97.

[19] M.R. Bohmer, L.K. Koopal, Adsorption of Ionic Surfactants on Variable-Charge Surfaces . 2 . Molecular Architecture and Structure of the Adsorbed Layer, Langmuir. 8 (1992) 2660-2665.

[20] S. Paria, K.C. Khilar, A review on experimental studies of surfactant adsorption at the hydrophilic solid-water interface, Adv. Colloid Interface Sci. 110 (2004) 75-95.

[21] R. Zhang, P. Somasundaran, Advances in adsorption of surfactants and their mixtures at solid/solution interfaces, Adv. Colloid Interface Sci. 123-126 (2006) 213-229. 


\section{ACCEPTED MANUSCRIPT}

[22] H. Domínguez, Self-aggregation of the SDS surfactant at a solid-liquid interface., J. Phys. Chem. B. 111 (2007) 4054-4059.

[23] H. Domínguez, Structural Transition of the Sodium Dodecyl Sulfate (SDS) Surfactant Induced by Changes in Surfactant Concentrations., J. Phys. Chem. B. 115 (2011) $12422-12428$.

[24] E. Núñez-Rojas, H. Domínguez, Computational studies on the behavior of sodium dodecyl sulfate (SDS) at TiO2(rutile)/water interfaces., J. Colloid Interface Sci. 364 (2011) 417-427.

[25] C.K. Yeom, S.H. Lee, J.M. Lee, Effect of the ionic characteristics of charged membranes on the permeation of anionic solutes in reverse osmosis, J. Memb. Sci. 169 (2000) 237-247.

[26] G. Cornelis, K. Boussu, B. Van Der Bruggen, I. Devreese, C. Vandecasteele, Nanofiltration of Nonionic Surfactants: Effect of the Molecular Weight Cutoff and Contact Angle on Flux Behavior, Ind. Eng. Chem. Res. 44 (2005) 7652-7658.

[27] H. Li, Y. Lin, P. Yu, Y. Luo, L. Hou, FTIR study of fatty acid fouling of reverse osmosis membranes: Effects of $\mathrm{pH}$, ionic strength, calcium, magnesium and temperature, Sep. Purif. Technol. 77 (2011) 171-178.

[28] K. Boussu, C. Kindts, C. Vandecasteele, B. Van der Bruggen, Surfactant fouling of nanofiltration membranes: measurements and mechanisms, ChemPhysChem. 8 (2007) $1836-1845$.

[29] C. Kamizawa, S. Ishizaka, Study on reverse osmosis. The permeation behavior of surfactant solution through cellulose acetate membranes, Bull. Chem. Soc. Jpn. 45 (1972) 2967-2969.

[30] E. Hinke, D. Laslop, E. Staude, The influence of charged surfactants upon reverse osmosis, Prog. Colloid Polym. Sci. 99 (1988) 94-99.

[31] E. Staude, E. Hinke, F. Malejka, Interactions in reverse osmosis of electrolyte/ charged surfactant solutions through porous membranes, Colloids and Surfaces. 42 (1989) 365374.

[32] C.Y. Tang, Q.S. Fu, A.P. Robertson, C.S. Criddle, J.O. Leckie, Use of reverse osmosis membranes to remove perfluorooctane sulfonate (PFOS) from semiconductor wastewater., Environ. Sci. Technol. 40 (2006) 7343-7349.

[33] A.E. Childress, S.S. Deshmukh, Effect of humic substances and anionic surfactants on the surface charge and performance of reverse osmosis membranes, Desalination. 118 (1998) 167-174. 


\section{ACCEPTED MANUSCRIPT}

[34] M.C. Kaplan, A. Jégou, B. Chaufer, M. Rabiller-Baudry, M.C. Michalsky, Adsorption of lysozyme on membrane material and cleaning with non-ionic surfactant characterized through contact angle measurements, Desalination. 146 (2002) 149-154.

[35] Y. Baek, J. Kang, P. Theato, J. Yoon, Measuring hydrophilicity of RO membranes by contact angles via sessile drop and captive bubble method: A comparative study, Desalination. 303 (2012) 23-28.

[36] M. Oldani, G. Schock, Characterization of ultrafiltration membranes by infrared spectroscopy, ESCA, and contact angle measurements, J. Memb. Sci. 43 (1989) 243258.

[37] N. Subhi, A.R.D. Verliefde, V. Chen, P. Le-Clech, Assessment of physicochemical interactions in hollow fibre ultrafiltration membrane by contact angle analysis, J. Memb. Sci. 403-404 (2012) 32-40.

[38] L. Gourley, M. Britten, S.F. Gauthier, Y. Pouliot, Characterization of adsorptive fouling on ultrafiltration membranes by peptides mixtures using contact angle measurements, J. Memb. Sci. 97 (1994) 283-289.

[39] Q. Li, X. Pan, Z. Qu, X. Zhao, Y. Jin, H. Dai, et al., Understanding the dependence of contact angles of commercially RO membranes on external conditions and surface features, Desalination. 309 (2013) 38-45.

[40] V. Gekas, K.M. Persson, M. Wahlgren, B. Sivik, Contact angles of ultrafiltration membranes and their possible correlation to membrane performance, J. Memb. Sci. 72 (1992) 293-302.

[41] C. Bellona, J.E. Drewes, P. Xu, G. Amy, Factors affecting the rejection of organic solutes during NF/RO treatment - a literature review, Water Res. 38 (2004) 2795-2809.

[42] A.R.D. Verliefde, E.R. Cornelissen, S.G.J. Heijman, E.M. V Hoek, G.L. Amy, B. Van der Bruggen, et al., Influence of solute-membrane affinity on rejection of uncharged organic solutes by nanofiltration membranes, Environ. Sci. Technol. 43 (2009) 24002406.

[43] D. Doulia, G. Tragardh, V. Gekas, Interaction behaviour in ultrafiltration of nonionic surfactants. Part II. Static adsorption below CMC, J. Memb. Sci. 123 (1997) 133-142.

[44] B. Wendler, B. Goers, G. Wozny, Nanofiltration of solutions containing surfactants prediction of flux decline and modelling of mass transfer, Desalination. 147 (2002) $217-221$. 


\section{ACCEPTED MANUSCRIPT}

[45] Y. Kaya, C. Aydiner, H. Barlas, B. Keskinler, Nanofiltration of single and mixture solutions containing anionics and nonionic surfactants below their critical micelle concentrations (CMCs), J. Memb. Sci. 282 (2006) 401-412.

[46] C.A. Basar, A. Karagunduz, A. Cakici, B. Keskinler, Removal of surfactants by powdered activated carbon and microfiltration, Water Res. 38 (2004) 2117-2124.

[47] M. Elimelech, X. Zhu, A.E. Childress, S. Hong, Role of membrane surface morphology in colloidal fouling of cellulose acetate and composite aromatic polyamide reverse osmosis membranes, J. Memb. Sci. 127 (1997) 101-109.

[48] M. Benrraou, B.L. Bales, R. Zana, Effect of the nature of the counterion on the properties of anionic surfactants. 1. $\mathrm{cmc}$, ionization degree at the $\mathrm{cmc}$ and aggregation number of micelles of sodium, cesium, tetramethylammonium, tetraethylammonium, Tetrapropylammonium, and tetrabutylammoniu, J. Phys. Chem. B. 107 (2003) 1343213440.

[49] O. Akin, F. Temelli, Probing the hydrophobicity of commercial reverse osmosis membranes produced by interfacial polymerization using contact angle, XPS, FTIR, FE-SEM and AFM, Desalination. 278 (2011) 387-396.

[50] C. Baudequin, Conception d'une unité mobile pour le post-traitement d'eau utilisée pendant des opérations d'extinction d'incendie, Ecole Centrale Paris, 2011.

[51] N. Wemsy Diagne, M. Rabiller-Baudry, L. Paugam, On the actual cleanability of polyethersulfone membrane fouled by proteins at critical or limiting flux, J. Memb. Sci. 425-426 (2013) 40-47.

[52] M. Cao, X. Song, J. Wang, Y. Wang, Adsorption of hexyl-alpha,omega-bis(dodecyldimethylammonium bromide) gemini surfactant on silica and its effect on wettability, J. Colloid Interface Sci. 300 (2006) 519-525.

[53] C.J. Van Oss, Development and applications of the interfacial tension between water and organic or biological surfaces, Colloids Surfaces B Biointerfaces. 54 (2007) 2-9.

[54] B. Mi, M. Elimelech, Organic fouling of forward osmosis membranes: Fouling reversibility and cleaning without chemical reagents, J. Memb. Sci. 348 (2010) 337345 .

[55] H.B. de Aguiar, M.L. Strader, A.G.F. de Beer, S. Roke, Surface structure of sodium dodecyl sulfate surfactant and oil at the oil-in-water droplet liquid/liquid interface: a manifestation of a nonequilibrium surface state, J. Phys. Chem. B. 115 (2011) 29702978. 


\section{ACCEPTED MANUSCRIPT}

[56] H. Nakahara, O. Shibata, Y. Moroi, Examination of surface adsorption of cetyltrimethylammonium bromide and sodium dodecyl sulfate, J. Phys. Chem. B. 115 (2011) 9077-9086.

[57] F. Pignon, G. Belina, T. Narayanan, X. Paubel, A. Magnin, G. Gésan-Guiziou, Structure and rheological behavior of casein micelle suspensions during ultrafiltration process, J. Chem. Phys. 121 (2004) 8138-8146.

[58] A. Bouchoux, P.-E. Cayemitte, J. Jardin, G. Gésan-Guiziou, B. Cabane, Casein micelle dispersions under osmotic stress, Biophys. J. 96 (2009) 693-706.

[59] A. Bouchoux, G. Gésan-Guiziou, J. Pérez, B. Cabane, How to squeeze a sponge: casein micelles under osmotic stress, a SAXS study, Biophys. J. 99 (2010) 3754-3762.

[60] C. David, F. Pignon, T. Narayanan, M. Sztucki, G. Gésan-Guiziou, Spatial and Temporal in Situ Evolution of the Concentration Profile during Casein Micelle Ultrafiltration Probed by Small-Angle X-ray Scattering, Langmuir. 24 (2008) 45234529. 